\title{
Chemokine Receptor 2-Mediated Accumulation of Fungicidal Exudate Macrophages in Mice That Clear Cryptococcal Lung Infection
}

\author{
John J. Osterholzer, ${ }^{\star \dagger \ddagger}$ Gwo-Hsiao Chen, ${ }^{, \dagger}$ \\ Michal A. Olszewski, ${ }^{\dagger \ddagger}$ Yan-Mei Zhang, ${ }^{\S}$ \\ Jeffrey L. Curtis, ${ }^{\star \dagger \ddagger}$ Gary B. Huffnagle, ${ }^{\dagger \neq}$ \\ and Galen B. Toews ${ }^{\star \dagger}$
}

that of AMs. We conclude that clearance of cryptococcal lung infection requires the CCR2-mediated massive accumulation of fungicidal ExMs derived from circulating Ly-6C $\mathrm{C}^{\text {high }}$ monocytes. (Am J Pathol 2011, 178:198-211; DOI: 10.1016/j.ajpath.2010.11.006)

Cryptococcus neoformans, an encapsulated yeast acquired by the respiratory tract, causes pneumonia and disseminated infection in patients with either compromised $^{1-3}$ or intact ${ }^{4-6}$ immune systems. Failure of antifungal therapy occurs, ${ }^{7}$ and novel immunotherapeutics or vaccines are needed. Murine models of cryptococcal lung infection have elucidated numerous host defense mechanisms contributing to the clearance of the organism. ${ }^{8,9}$ Clearance requires the development of an adaptive immune response characterized by interferon (IFN) $\gamma$ production, ${ }^{9-17}$ which activates lung macrophages and enhances their antifungal effector functions, including production of inducible nitric oxide synthase (iNOS) and tumor necrosis factor (TNF) $\alpha .^{16-24}$

The origin and phenotype of this effector macrophage population have not been well characterized. Resident alveolar macrophages (AMs), the dominant macrophage population in the unperturbed murine lung, ingest cryptococci but kill inefficiently. ${ }^{21}$ The intracellular sequestra-

Supported by the Biomedical Laboratory Research and Development Service, Department of Veterans Affairs (Career Development Award-2 to J.J.O and Merit Review Awards) (G.B.T. and M.A.O.); and by the US Public Health Service grants RO1-HL065912 and RO1-Al059201 (G.B.H.), grant RO1HL051082 (G.B.T.), and grant R01 HL056309 (J.L.C.).

Accepted for publication September 2, 2010.

Portions of this study have been presented previously at the International Conference of the American Thoracic Society, May 20, 2009, San Diego, CA; and were published in abstract form (Am J Respir Crit Care Med 2009, 179:A6079).

Supplemental material for this article can be found at $h$ ttp://ajp. amjpathol. org and at doi:10.1016/j.ajpath.2010.11.006.

Address reprint requests to John J. Osterholzer, M.D., Pulmonary and Critical Care Medicine Section (111G), Department of Veterans Affairs Medical Center, 2215 Fuller Rd, Ann Arbor, Ml 48105-2303. E-mail: oster@umich.edu. 
tion of viable cryptococci within AMs contributes to propagation of infection during the pre-effector phase of the host response [approximately $0-14$ days post-infection (dpi)] ${ }^{25-29}$ Yet, AMs also protect against deleterious and ineffective inflammation before the onset of adaptive immunity. ${ }^{30}$ Previous studies ${ }^{31,32}$ identified macrophage accumulation in the lungs of cryptococcal-infected mice during the effector phase (approximately 14-28 dpi) of the host response. Impaired cryptococcal clearance in chemokine receptor 2 (CCR2)-deficient mice correlates strongly with diminished pulmonary macrophage accumulation. However, these observations were made by visual identification of macrophages by light microscopy, which neither distinguishes resident from nonresident cells nor provides further insight into the phenotype or function of this critical cell population.

Flow cytometric analysis was recently used to identify exudate macrophages (ExMs) as a nonresident macrophage population accumulating in the lungs of mice with bacterial or viral pneumonia. ${ }^{33-36}$ Expression of CD11b, along with varying reports of increased major histocompatibility complex (MHC) class II and costimulatory molecules, distinguishes ExMs from AMs. ${ }^{33}$ Exudate macrophages express iNOS indicative of effector function. ${ }^{34}$ Whether ExMs are present in mice with cryptococcal lung infection is unknown.

In this study, we investigated the role of macrophages in host defense against cryptococcal lung infection using $\mathrm{BALB} / \mathrm{c}$ mice that clear the infection beginning $14 \mathrm{dpi}$ in this established model system. ${ }^{31,32,37}$ We used six- to eight-parameter flow cytometric analysis to assess the relative prevalence and phenotype of AMs and ExMs during the pre-effector and effector phases of the host response to infection and determined whether AMs or ExMs proliferate in the lungs of infected mice. We then performed a comparative analysis using gene-targeted mice deficient in CCR2 (CCR2 ${ }^{-1-}$ mice; BALB/c genetic background) to determine whether accumulation of ExMs requires the recruitment and differentiation of blood monocytes. Finally, we specifically evaluated $\mathrm{AM}$ and ExM effector functions. Our results show that pulmonary clearance of a eukaryotic fungal pathogen requires the CCR2-mediated massive accumulation of fungicidal ExMs derived from Ly- $6 C^{\text {high }}$ monocytes.

\section{Materials and Methods}

\section{Mice}

Specific pathogen-free, inbred, female, wild-type BALB/c mice (designated CCR2 $2^{+/+}$in experiments involving direct comparison with $\mathrm{CCR} 2^{-1-}$ mice), purchased from Charles River Laboratory Inc, Wilmington, MA, were used, except as specified. The $\mathrm{CCR}^{-1-}$ mice [C57BL/6 × J129 (C57) J129)] back crossed eight times onto a BALB/c background were provided by W. Kuziel, Molecular Genetics and Microbiology, University of Texas, Austin, ${ }^{38}$ and were bred on site. Mice were housed in the Animal Care Facility at the Ann Arbor Veterans Affairs Health System and were cared for using a protocol approved by the local Department of Veterans Affairs Institutional Animal Care and Use
Committee. Mice were aged 8 to 12 weeks at infection, and there were no age-related differences in the responses of these mice to $C$. neoformans infection.

\section{Cryptococcus neoformans}

Cryptococcus neoformans strain 52D was obtained from the American Type Culture Collection (24067; Manassas, VA); this strain displayed smooth colony morphological features when grown on Sabouraud dextrose agar before inoculation and on recovery from infected mice. For infection, yeast were grown to a stationary phase (for $48-72$ hours) at $37^{\circ} \mathrm{C}$ in Sabouraud dextrose broth $(1 \%$ neopeptone and 2\% dextrose; DIFCO, Detroit, MI) on a shaker. Cultured C. neoformans was then washed in nonpyrogenic saline, counted using Trypan blue on a hemocytometer, and diluted to $3.3 \times 10^{5} \mathrm{cryptococci} / \mathrm{ml}$ in sterile nonpyrogenic saline.

\section{Surgical i.t. Inoculation}

Mice were anesthetized by i.p. injection of ketamine (100 $\mathrm{mg} / \mathrm{kg}$; Fort Dodge Laboratories, Fort Dodge, IA) and xylazine (6.8 mg/kg; Lloyd Laboratories, Shenandoah, IA) and restrained on a surgical board. A small incision was made through the skin over the trachea, and the underlying tissue was separated. A 30-gauge needle was attached to a 1-ml tuberculin syringe filled with diluted $C$. neoformans culture. The needle was inserted into the trachea, and a $30-\mu \mathrm{L}$ inoculum $\left[10^{4}\right.$ colony-forming units (CFUs)] was dispensed into the lungs. The needle was removed, and the skin was closed with cyanoacrylate adhesive. The mice recovered with minimal visible trauma.

\section{Monoclonal Antibodies}

The following monoclonal antibodies (mAbs) were purchased from BioLegend, San Diego, CA: N418 (antimurine CD11c, hamster IgG1), 2.4G2 ("Fc block") (antimurine CD16/CD32, rat IgG2b), 30-F11 (anti-murine CD45, rat IgG2b), 16-10A1 (anti-murine CD80, hamster IgG2), GL1 (anti-murine CD86, rat IgG2a), AMS-32.1 ("MHC class II") (anti-murine I-A ${ }^{d}$, mouse IgG2b), 1452C11 (anti-murine CD3e, hamster IgG1, $\kappa$ ), 6D5 (antimurine CD19, rat IgG2a), M3/38 (anti-murine Mac-2, rat IgG2a), M3/84 [anti-murine CD107b (Mac-3), rat IgG1], and BM8 (anti-murine F4/80, rat IgG2a). The following mAbs were purchased from BD Biosciences PharMingen, San Diego: AL-21 (anti-murine Ly-6C, rat IgM), $\mathrm{M} 1 / 70$ (anti-murine CD11b, rat IgG2b), 3/23 (anti-murine CD40, rat IgG2a), and clone 6 (anti-murine iNOS/NOS). The following mAbs were purchased from Cedarlane Laboratories, Burlington, NC: 2F8 (anti-murine CD204, rat IgG2b) and NLDC-145 (anti-murine CD205, rat IgG2a). The mAbs were primarily conjugated with fluorescein isothiocyanate, phosphatidylethanolamine, peridinin chlorophyll protein - Cyanine 5.5, allophycocyanin, allophycocyanincyanine 7, or Pacific blue. Isotype-matched irrelevant control mAbs (BioLegend) were tested simultaneously in all experiments. 


\section{Ab Staining and Flow Cytometric Analysis}

Staining, including blockade of Fc receptors, and analysis by flow cytometry were performed as previously described. ${ }^{39,40}$ Data were collected on a flow cytometer (BD LSR II) using computer software (FACSDiva; both from Becton Dickinson Immunocytometry Systems, Mountain View, CA) and analyzed using additional software (FlowJo; Tree Star Inc, San Carlos, CA). Numerous cells $(10,000-$ $100,000)$ were analyzed per sample. In selected experiments, fluorescence-activated cell sorting of specific lung macrophage populations was performed using a flow cytometer (BD ARIA) and software (FACSDiva).

Specific gating strategies identifying macrophage and monocyte subsets are described in detail in the Results section. To maintain complete consistency, cytometer parameters and gate position were held constant during analysis of all samples. Total numbers of each cell population within each tissue were calculated by multiplying the frequency of the population by the total number of leukocytes (the percentage of $\mathrm{CD}_{4} 5^{+}$cells multiplied by the original hemocytometer count of total cells) identified within that sample.

\section{Tissue Collection}

Lungs were perfused via the right heart using PBS containing $0.5 \mathrm{mmol} / \mathrm{L}$ EDTA until pulmonary vessels were grossly clear. Lungs were then excised, minced, and enzymatically digested to obtain a single-cell suspension of lung leukocytes. ${ }^{41}$ The peripheral blood mononuclear cells were isolated from peripheral blood obtained from the retro-orbital vein of deeply anesthetized mice and processed as previously described. ${ }^{42}$ Spleens were excised and leukocytes were dispersed by mincing and mechanical disruption. Bone marrow was harvested by removing the ends from both femurs with a number 10 blade scalpel (after removal of skin and muscle) and flushing the marrow with $2 \mathrm{ml}$ of PBS, using a 3-ml syringe and a 251/2-gauge needle, into a sterile $100 \times 15-\mathrm{mm}$ dish; leukocytes were dispersed further by mechanical disruption. After erythrocyte lysis, cells were washed, filtered over 70- $\mu \mathrm{m}$ mesh, and resuspended in complete medium. Total numbers of viable lung, peripheral blood, spleen, and bone marrow leukocytes were assessed in the presence of Trypan blue using a hemocytometer. All cell preparations were washed twice in PBS before use for antibody staining.

\section{Evaluation of Macrophage Proliferation in Vivo}

A flow cytometry assay kit (Click-iT EdU Pacific Blue; catalogue number A10034) was purchased from Invitrogen, Carlsbad, CA, for the labeling and detection of DNA synthesis. This labeling strategy uses the incorporation of the thymidine analogue 5-ethynyl-2'-deoxyuridine (EdU), followed by chemical coupling of the analogue with an azide-conjugated flurophore for detection. Mice were injected i.p. with either $100 \mu \mathrm{g}$ of EdU in PBS or PBS alone (negative control) at $10 \mathrm{dpi}$, the time of maximal ExM accumulation in the lung. After 2 hours, mice were sacrificed and bone marrow cells (as positive control) and specific lung leukocyte populations identified by flow cy- tometric analysis were evaluated for EdU uptake following manufacturer's protocols and as previously described. ${ }^{43-46}$ Gates depicting positive uptake were set based on the staining characteristics of control leukocytes obtained from infected mice not receiving EdU. The assay was further validated by measuring EdU incorporation in polymorphonuclear neutrophils (defined as SSCmoderate-high $\mathrm{Ly}-6 \mathrm{C}^{\text {moderate }} \mathrm{CD} 11 \mathrm{~b}^{+}$), which proliferate in bone marrow but not on arrival in the lung. ${ }^{47}$

\section{In Vitro Culture of Ly-6C $C^{\text {high }}$ Monocytes}

Purified Ly-6Chigh myeloid cells, obtained from the bone marrow of uninfected $\mathrm{CCR} 2^{+/+}$mice, as previously described ${ }^{45}$ were cultured and differentiated at $3 \times 10^{5}$ cells $/ \mathrm{ml}$ in the presence of $20-\mathrm{ng} / \mathrm{ml}$ Granulocyte Macrophage - Colony Stimulating Factor (GM-CSF) (PeproTech, Rocky Hill, NJ) in complete medium (previously defined). After 7 days, the resultant nonadherent cell populations were discarded and the remaining adherent cells were removed by cell scraping after incubation on ice for 20 minutes in PBS containing $1 \mathrm{mmol} / \mathrm{L}$ EDTA. Adherent cells were compared with freshly isolated cells [designated day 0 (D0)] using flow cytometry for the expression of Ly-6C, CD11C, and CD11b.

In additional experiments, adherent $\mathrm{CD} 11 \mathrm{c}^{+} \mathrm{CD} 11 \mathrm{~b}^{+}$ cells were assessed for the expression of macrophageassociated markers (F4/80, Mac-2, Mac-3, and CD204) and costimulatory molecules (CD80 and CD86). These $\mathrm{CD}_{11 \mathrm{c}^{+}} \mathrm{CD}_{111 \mathrm{~b}^{+}}$cells were resultant from culture of Ly- $6 C^{\text {high }}$ bone marrow-derived myeloid cells in complete medium under either of two conditions: i) GM-CSF alone for 7 days or ii) GM-CSF for 7 days plus heat-killed C. neoformans strain 602 at a 1:2 ratio of cells/heat-killed C. neoformans strain 602 on day 6 of culture. Adherent cells from all cultures were removed for analysis on day 7 .

\section{In Vitro Macrophage Stimulation and Nitrite Production Assay}

AMs and ExMs isolated from cryptococcal-infected BALB/C mice (at $14 \mathrm{dpi}$ ) by cell sorting were cultured in 96-well plates $\left(1 \times 10^{5}\right.$ macrophages/200 $\mu \mathrm{L}$ complete medium) either alone or in the presence of heat-killed $C$. neoformans strain 602 (at a 1:3 ratio of macrophages/Cryptococcus). Supernatants were removed after 24 hours of culture. Thereafter, $100-\mu \mathrm{L}$ Griess reagent $(0.1 \%$ napthylethylenediamine in water and $1 \%$ sulfanilamide in $5 \%$ orthophosphoric acid; Sigma, Aldrich, St. Louis, MO) was added to $100-\mu \mathrm{L}$ experimental supernatants or $100-\mu \mathrm{L}$ sodium nitrite standard $(0-100 \mu \mathrm{mol} / \mathrm{L}){ }^{48}$ The mixture was incubated at room temperature for 10 minutes, and the absorbance was measured at $550 \mathrm{~nm}$. Nitrite concentrations of experimental samples were determined by reference to a standard curve constructed in parallel.

\section{TNF- $\alpha$ Production}

Culture supernatants derived from AM and ExM cultures (previously described) were assayed for TNF- $\alpha$ production by 
sandwich enzyme-linked immunosorbent assay (R\&D Systems, Minneapolis, MN) using the manufacturer's instructions.

\section{$R T-P C R$}

Total lung or macrophage-specific RNA was prepared using a kit (RNeasy Plus Mini Kit; Qiagen, Valencia, CA), and cDNA was synthesized using (SuperScriptIII; Invitrogen), according to the manufacturer's instructions. Cytokine mRNA was quantified with SYBR Green-based detection using a system (MX 3000P; Stratagene, La Jolla, CA), according to the manufacturer's protocols. Forty cycles of PCR $\left(94^{\circ} \mathrm{C}\right.$ for 15 seconds, followed by $60^{\circ} \mathrm{C}$ for 30 seconds and $72^{\circ} \mathrm{C}$ for 30 seconds) were performed on a cDNA template. The mRNA levels were either i) expressed as a ratio of their relative abundance to $\beta$-actin or ii) normalized to glyceraldehyde-3-phosphate dehydrogenase and expressed as fold induction compared with uninfected mouse expression level assigned as 1 . The following murine oligonucleotide primers were used for RT-PCR analysis: Arg-1 sense, 5'-CAGAAGAATGGAAGAGTCAG-3'; Arg-1 antisense, 5'-CAGATATGCAGGGAGTCACC-3'; inducible NO synthase (iNOS) sense, 5'-TTTGCTTCCATGCTAATGCGAAAG-3'; iNOS antisense, 5'-GCTCTGTTGAGGTCTAAAGGCTCCG-3'; YM2 sense, 5'-CAGAACCGTCAGACATTCATTA3': YM2 antisense; 5'-ATGGTCCTTCCAGTAGGTAATA-3'; FIZZ1 sense, 5'-GGTCCCAGTGCATATGGATGAGACCATAGA-3'; FIZZ1 antisense, 5'-CACCTCTTCACTCGAGGGACAGTTGGCAGC-3'; glyceraldehyde-3-phosphate dehydrogenase sense, 5'-TATGTCGTGGAGTCTACTG-3'; glyceraldehyde-3-phosphate dehydrogenase antisense, 5'-GAGTTGTCATATTTCTCGT-3'; TNF- $\alpha$ sense, 5'CCTGTAGCCCACGTCGTAGC-3'; TNF- $\alpha$ antisense, 5'AGCAATGACTCCAAAGTAGACC-3'; $\beta$-actin sense, $5^{\prime}$ TGGAATCCTGTGGCATCC-ATGAAAC-3'; and $\beta$-actin antisense, 5'-TAAAACGCAGCTCAGTAACAGTCCG-3'.

\section{Quantification of Intracellular C. neoformans from Sorted Macrophage Populations}

AMs and ExMs isolated from cryptococcal-infected BALB/c mice (at $14 \mathrm{dpi}$ ) by fluorescence-activated cell sorting were adjusted to $10^{5}$ cells/well and lysed with $0.1 \%$ Triton $X-100$ to release viable cryptococci phagocytosed by macrophages in vivo. Prior experiments demonstrate that $0.1 \%$ Triton does not affect cryptococcal growth. ${ }^{49}$ Cultures were then maintained for 24 hours, when fungal growth was assessed by CFU assay to determine the average number of cryptococci per macrophage at macrophage isolation from the lung.

\section{C. neoformans Killing Assay}

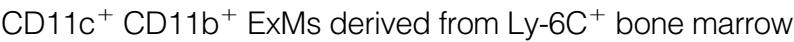
monocytes were generated as previously described from naive CCR2 $2^{+/+}$mice or $\mathrm{CCR} 2^{-1-}$ mice under one of two conditions: i) GM-CSF alone for 7 days or ii) GM-CSF for 7 days plus IFN- $\gamma(20 \mathrm{ng} / \mathrm{ml})$ and TNF- $\alpha(20 \mathrm{ng} / \mathrm{ml})$ on day 6 . At day 7 , the adherent population of ExMs was removed, and the fungicidal activity of these cells was assessed by
CFU assay after 24-hour culture at a 100:1 effector to target ratio with live $C$. neoformans strain 52D. The fungicidal activity of these ExMs was compared with that of fresh AMs obtained by bronchoalveolar lavage from the lungs of naïve wild-type $\left(\mathrm{CCR}^{+/+}\right)$mice. The AMs were tested after 24hour culture in complete medium alone or medium containing IFN- $\gamma(20 \mathrm{ng} / \mathrm{ml})$ and TNF- $\alpha(20 \mathrm{ng} / \mathrm{ml})$.

\section{Statistical Analysis}

All data were expressed as mean \pm SEM. Continuous ratio scale data were evaluated by unpaired Student's $t$-test (for comparison between two samples) or by analysis of variance (for multiple comparisons) with post hoc analysis by two-tailed Dunnett's test, which compares treatment groups with a specific control group. ${ }^{50}$ Statistical calculations were performed on a computer (Dell 270) using software (GraphPad Prism version 3.00 for Windows; GraphPad Software, San Diego). Statistical difference was accepted at $P<0.05$.

\section{Results}

CD11 ${ }^{+}$CD11 $^{+}$Autofluorescent ExMs Are the Most Prevalent Lung Macrophage Population in Mice that Clear Cryptococcal Lung Infection

We first used antibody staining and multiparameter flow cytometric analysis (please see the Materials and Methods, section Ab Staining and Flow Cytometric Analysis) to identify specific macrophage populations in the lungs of cryptococcal-infected wild-type (BALB/c) mice that clear cryptococcal lung infection. Initial gates eliminated debris, red cells, and cell clusters and selected for $\mathrm{CD} 45^{+}$leukocytes. T cells, B cells, and eosinophils were excluded ${ }^{41,51}$ (data not shown). Next, we set consecutive gates which identified $\mathrm{CD}_{11 \mathrm{C}^{+}}$cells (Figure 1A, left dot plot) and distinguished autofluorescent $\left(\mathrm{AF}^{+}\right)$macrophages from non- $\mathrm{AF}\left(\mathrm{AF}^{-}\right)$ dendritic cells (DCs) (Figure 1A, middle dot plot), as previously described. ${ }^{41,45,51-53}$ Last, we used relative expression of $\mathrm{CD} 11 \mathrm{~b}$ to distinguish CD11b-negative AMs $\left(\mathrm{CD}_{11 \mathrm{c}^{+}} \mathrm{AF}^{+} \mathrm{CD} 11 \mathrm{~b}^{-}\right)^{42,54,55}$ and CD11b-positive ExMs $\left(\mathrm{CD}_{11 \mathrm{c}^{+}} \mathrm{AF}^{+} \mathrm{CD}^{+11 \mathrm{~b}^{+}}\right)^{33,35}$ (Figure 1A, right dot plot; gates labeled $A M$ and ExM). Proper gate placement for $\mathrm{AF}$ and expression of CD11c and CD11b were determined using AMs obtained from bronchoalveolar lavage fluid of uninfected mice (which consists of $>90 \%$ $\mathrm{CD}_{11 \mathrm{C}^{+}} \mathrm{AF}^{+} \mathrm{CD}_{11 \mathrm{~b}^{-}} \mathrm{AMs}$; data not shown). AMs were prevalent in uninfected mice (Figure 1A, right dot plot). In contrast, ExMs appeared enriched in the lungs of mice at $14 \mathrm{dpi}$ (Figure 1B, right dot plot).

Both AMs and ExMs displayed high forward scatter and side scatter, typical of macrophages (Figure 1C). Visual inspection of cytospins prepared from sorted populations confirmed that both AMs and ExMs were large cells (12-18 $\mu \mathrm{m}$ ) with abundant cytoplasm and round/oval nuclei (Figure 1D). AMs displayed largely smooth cell membranes and contained few intracellular vacuoles. In contrast, ExMs had highly invaginated cell membranes, some of which seemed adherent to individual cryptococci. Many ExMs contained 
A

DO
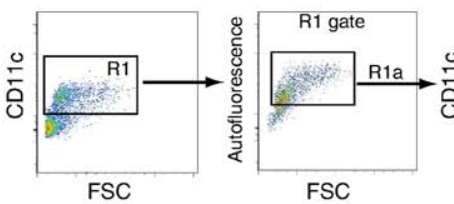

FSC

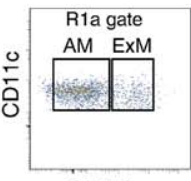

CD11b

B

D14
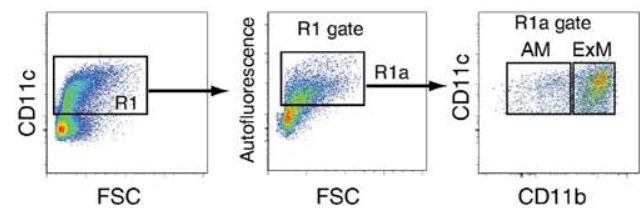

$E$

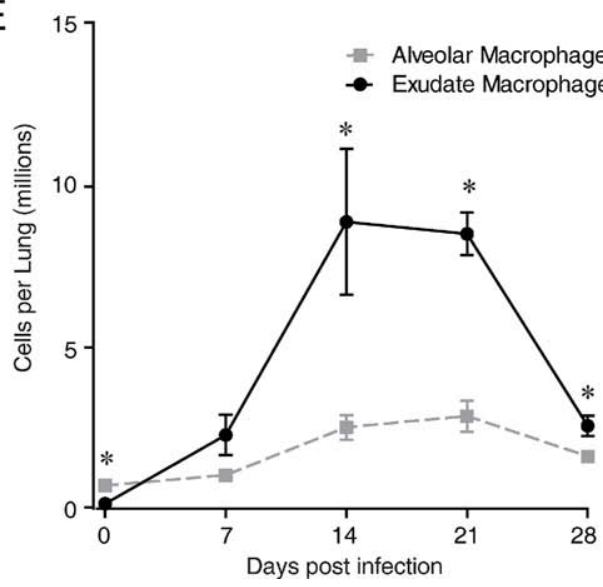

C

AM
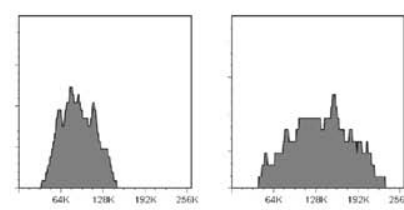

D
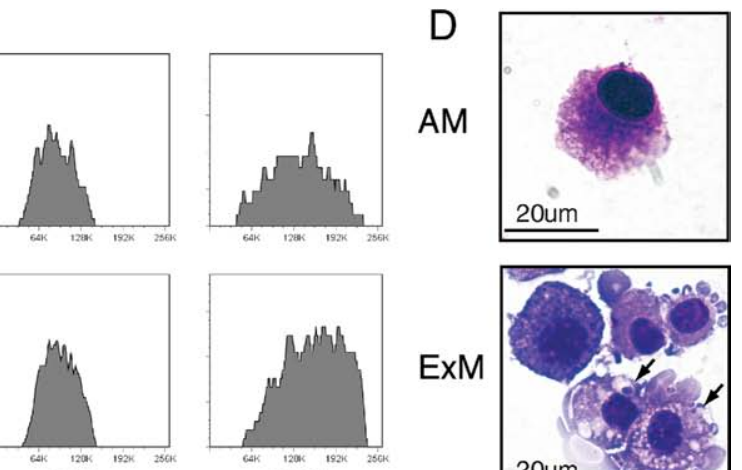

FSC

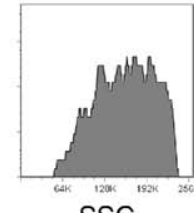

SSC

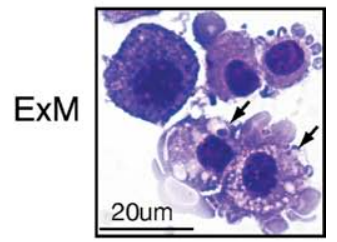

Figure 1. ExMs are the most prevalent macrophage population in the lungs of mice that clear infection with C. neoformans. Lung leukocytes obtained from wild-type (BALB/c) mice that were either uninfected (designated D0) or at various dpi with $C$. neoformans were stained with specific antibodies and either analyzed by flow cytometric analysis $(\mathbf{A}-\mathbf{C}$ and $\mathbf{E})$ or sorted and prepared by cytospin (D), as described in the Materials and Methods, section Ab Staining and Flow Cytometric Analysis. A and B: Gating strategy used to identify AMs and ExMs among lung leukocytes obtained from uninfected mice $(\mathbf{A})$ or mice at $14 \mathrm{dpi}(\mathbf{B})$. Initial gating on $\mathrm{CD} 45^{+}$lung leukocytes excludes debris, lymphocytes, and eosinophils (not shown). Next, a plot of CD11c versus FSC identifies CD11 $\mathrm{c}^{+}$cells (left dot plots, gate R1). Within the CD11 $\mathrm{C}^{+}$populations, a plot of FL-3 versus FSC (middle dot plots) distinguishes $\mathrm{AF}$ macrophages $\left(\mathrm{AF}^{+}\right.$, gate R1a) from non-AF DCs. Among $\mathrm{AF}^{+}$macrophages, a plot of $\mathrm{CD} 11 \mathrm{c}$ versus $\mathrm{CD} 11 \mathrm{~b}$ distinguishes $\mathrm{AMs}$ (right dot plots; $\mathrm{CD} 11 \mathrm{c}^{+} \mathrm{AF}^{+} \mathrm{CD} 11 \mathrm{~b}^{-}$, gate $\mathrm{AM}$ ) and ExMs (right dot plots; CD11c ${ }^{+} \mathrm{AF}^{+} \mathrm{CD} 11 \mathrm{~b}^{+}$, gate ExM). AMs appear more prevalent in uninfected mice, whereas a dense population of ExMs is identified in the lungs of infected mice. C: Representative histograms depicting the forward scatter (FSC; left histograms) and side scatter (SSC; right histograms) properties of AMs (top histograms) and ExMs (bottom histograms). D: Representative photomicrographs of AMs (top) and ExMs (bottom) obtained by flow sorting of lung leukocytes at $14 \mathrm{dpi}$ ( $\times 100$ objective; hematoxylin-eosin stain). ExMs are large cells displaying invaginated membranes that contain numerous foamy vacuoles and occasional intracellular cryptococci (arrows). E: Total numbers of AMs and ExMs present in the lungs of uninfected mice (D0) or at 7, 14, 21, and 28 dpi with C. neoformans. Total numbers were calculated by multiplying the frequency of each population (using the gating strategy previously described) by the total number of $\mathrm{CD} 45^{+}$lung leukocytes at each point. Data represent the mean \pm SEM of five to eight mice assayed individually per point AM, gray dashed lines; ExM, black solid lines; ${ }^{*} P<0.05$ by unpaired Student's $t$-test for ExM versus AM mice at the same point. The time course was repeated once $(n=3$ mice per strain per point) in its entirety with similar results.

ingested cryptococci within cytoplasmic vacuoles, consistent with phagocytic function.

We then applied this gating strategy to quantify the numbers of AMs and ExMs in the lungs of uninfected mice (D0) or mice at 7-day intervals after infection with C. neoformans. As expected, ${ }^{31,32,41,45}$ infection stimulated a substantial accumulation (22-fold relative to D0) of lung leukocytes, peaking at $14 \mathrm{dpi}\left(1.1 \pm 0.2 \times 10^{8} \mathrm{CD} 45^{+}\right.$leukocytes per lung). AMs were more numerous than ExMs in uninfected mice (Figure 1E) but demonstrated only a modest fivefold increase relative to $\mathrm{D} 0$, peaking at $21 \mathrm{dpi}(3.5 \% \pm 1.0 \%$ of total CD45 ${ }^{+}$leukocytes and $\left.3.6 \pm 0.5 \times 10^{6} \mathrm{AMs} / \mathrm{lung}\right)$. In contrast, ExM numbers massively increased 60 -fold relative to D0, peaking at $14 \mathrm{dpi}\left(7.6 \% \pm 0.1 \%\right.$ of total CD45 ${ }^{+}$ leukocytes and $8.9 \pm 2.3 \times 10^{6}$ ExMs/lung). ExMs significantly outnumbered AMs at 14, 21, and 28 dpi, coinciding with the time of maximal cryptococcal clearance in this model. ${ }^{32}$ Thus, ExMs are the most prevalent lung macrophage population present in mice during the effector response against cryptococcal lung infection.

\section{ExMs Express Numerous Macrophage-Associated Proteins, MHC Class II, and Costimulatory Molecules}

AMs and ExMs were evaluated for expression of molecules associated with pathogen recognition and phago- cytosis, including F4/80 (a G protein-coupled receptor of the epidermal growth factor-TM7 family), Mac-3 (also known as Lamp2 or CD107b), CD204 (scavenger receptor A I/II), and CD205 (DEC205) during either the preeffector (7 dpi) or effector (14 and $21 \mathrm{dpi}$ ) phase of the host response against $C$. neoformans (Figure 2A). AMs initially expressed F4/80, Mac-3, and CD204, which decreased at $14 \mathrm{dpi}$. In contrast, expression of Mac-2 and CD205 was low (at 7 dpi) but increased by 14 dpi. ExMs expressed more F4/80 and CD204 than the AMs at 7 dpi. Similar to AMs, ExM expression of F4/80, Mac-3, and CD204 decreased at 14 dpi, whereas Mac-2 and CD205 increased. At $21 \mathrm{dpi}$, the expression of these molecules was similar to the pattern observed at $14 \mathrm{dpi}$ for both AMs and ExMs (see Supplemental Figure S1A at http://ajp. amjpathol.org).

In a similar fashion, we also evaluated $A M$ and ExM expression of $\mathrm{MHC}$ class $\|\left(\mathrm{I}-\mathrm{A}^{\mathrm{d}}\right)$ and the costimulatory molecules CD40, CD80, and CD86 (Figure 2B). At 7 dpi, AMs expressed some MHC class II and CD80 but minimal CD40 or CD86; only MHC class II increased to a modest amount by $14 \mathrm{dpi}$. In contrast, ExMs expressed much higher amounts of MHC class II, CD40, and CD86 than AMs at 7 dpi. Interestingly, ExM expression of MHC class II remained high (at $14 \mathrm{dpi}$ ), whereas expression of CD40, CD80, and CD86 decreased. At $21 \mathrm{dpi}$, trends toward a further reduction in expression of $\mathrm{MHC}$ class II, CD40, and 
A

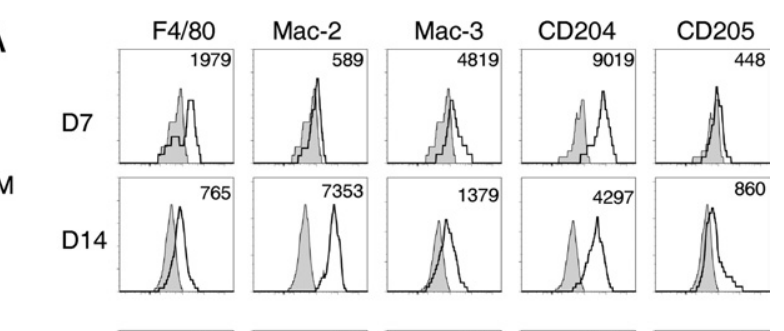

ExM
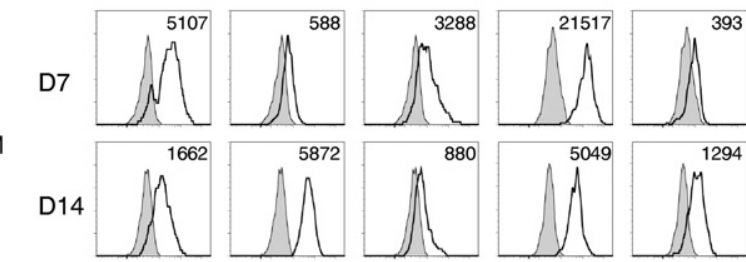

B

B

$\mathrm{AM}$
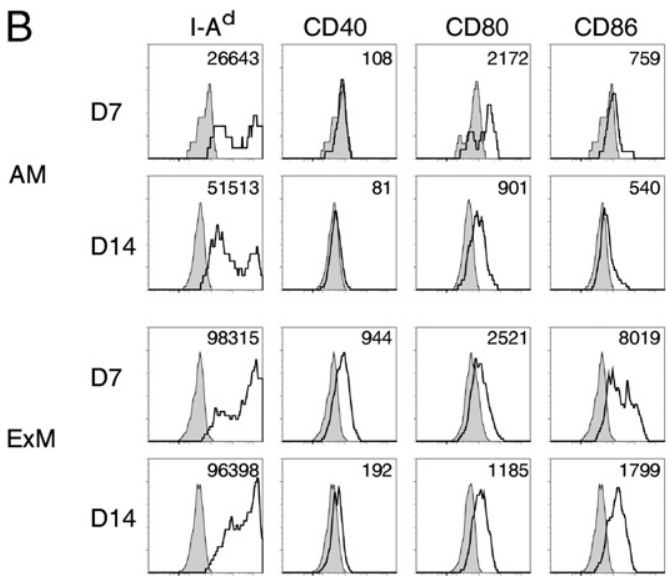

Figure 2. Cell surface phenotype of AMs and ExMs in the lungs of mice infected with C. neoformans. Lung leukocytes obtained from wild-type mice at 7 and $14 \mathrm{dpi}$ with C. neoformans were identified using the gating strategy described in the legend to Figure 1. Representative histograms (four-decade $\log$ scale) of AMs or ExMs from individual mice displaying their expression of macrophage-associated proteins (F4/80, Mac-2, Mac-3, CD204, and CD205) (A) and MHC class II (I-A ${ }^{\mathrm{d}}$ ) and costimulatory molecules (CD40, CD80, and CD86) (B). Shaded histogram, isotype staining; open histogram, specific staining. Numbers located above the histograms represent the change in mean fluorescent intensity (MFI) between specific antibody and isotype staining. The experiment was performed three times with similar results.

CD86 were observed for both AMs and ExMs, whereas CD80 expression was stable (see Supplemental Figure S1B at $h$ ttp://ajp.amjpathol.org). Collectively, these data demonstrate that both AMs and ExMs express macrophage markers associated with pathogen recognition and phagocytosis in a similar fashion. However, ExMs are distinguished from AMs by their stronger expression of MHC class II and costimulatory molecules, suggesting that these macrophages may be more uniquely equipped to participate in the effector arm of the adaptive immune response. The expression of these molecules is not static; it varies at different phases of the effector response against $C$. neoformans.

\section{ExMs Are Not Proliferating at the Time of Their Peak Accumulation in the Lungs of Mice Infected with $\mathrm{C}$. neoformans}

Next, we determined whether in situ proliferation contributed to macrophage accumulation in this model. Lung
Table 1. Proliferation of Bone Marrow and Lung Leukocytes*

\begin{tabular}{cc}
\hline Leukocytes & \% Positive for EdU \\
\hline Bone marrow & \\
Total cells & $16.6 \pm 0.5^{\ddagger}$ \\
PMNs & $11.0 \pm 1.1^{\ddagger}$ \\
Lung & \\
AMs & $1.0 \pm 0.6$ \\
ExMs & $-0.2 \pm 0.3$ \\
PMNs & $-0.1 \pm 0.3$
\end{tabular}

PMN, polymorphonuclear neutrophil.

${ }^{*}$ Cells were identified, per the Materials and Methods section Ab Staining and Flow Cytometric Analysis and Figure 1. The experiment was repeated with similar results.

${ }^{\dagger}$ Data are given as the mean \pm SEM of three cryptococcal-infected wild-type (BALB/c) mice assayed individually at $10 \mathrm{dpi}$.

${ }^{\ddagger} P<0.05$ by unpaired Student $t$-test comparing EdU expression from EdU-treated mice versus untreated (but infected) controls.

leukocyte proliferation was evaluated during maximal ExM accumulation in the lung (between 7 and $14 \mathrm{dpi}$ ). We used an established assay that measures EdU incorporation into replicating cells using flow cytometric analysis (per the Materials and Methods section Evaluation of Macrophage Proliferation In Vivo). ${ }^{43-46}$ Within bone marrow, we clearly identified a population of proliferating leukocytes, including polymorphonuclear neutrophils (positive control), whereas among lung leukocyte populations, AMs, ExMs, and polymorphonuclear neutrophils (negative control ${ }^{47}$ ) were not proliferating (Table 1). Collectively, these data indicate that the substantial accumulation of ExMs (and AMs) during cryptococcal infection is not attributable to macrophage proliferation within the lung.

\section{ExMs Strongly Express Ly-6C during the Early Phase of Their Accumulation in the Lungs of Mice Infected with $\mathrm{C}$. neoformans}

The absence of ExM proliferation in the lung suggested that massive ExM accumulation required the recruitment and differentiation of a myeloid precursor. Therefore, we evaluated ExM expression of the cell surface molecule Ly-6C as a marker of newly differentiated myeloid cells. ${ }^{33,56,57}$ ExMs recovered at 7 dpi strongly express Ly-6C, whereas expression was diminished at 14 and 21 dpi (Figure 3). By 28 dpi, the few remaining ExMs expressed almost no Ly-6C. These data suggest that ExMs present during the pre-effector response

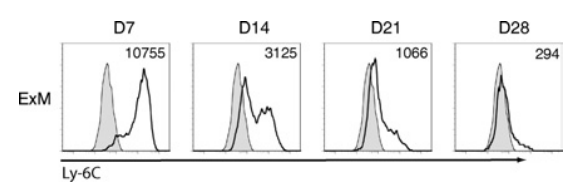

Figure 3. ExMs strongly express Ly-6C at early points after pulmonary infection with $C$. neoformans. Representative histograms express Ly-6C on ExMs recovered from the lungs of wild-type mice at 7, 14, 21, and 28 dpi with C. neoformans. Shaded histogram, isotype staining; open histogram, specific staining. Numbers located above the histograms represent the change in mean fluorescent intensity (MFI) between specific antibody and isotype staining. Expression of Ly-6C is highest at day 7 and is diminished thereafter. The experiment was performed three times with similar results. 
A
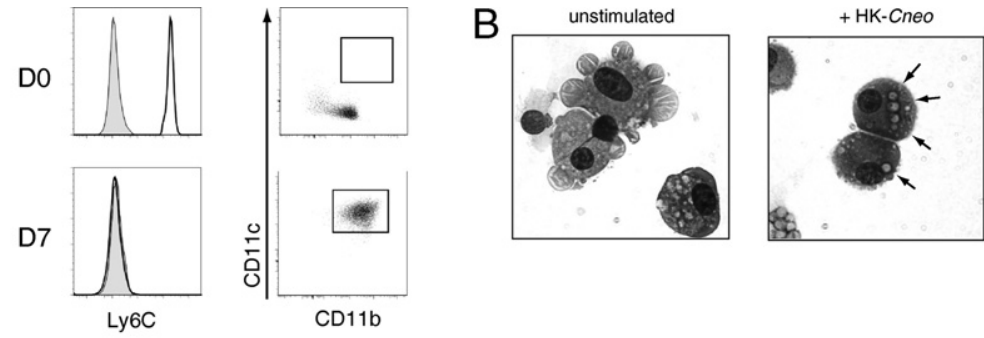

C
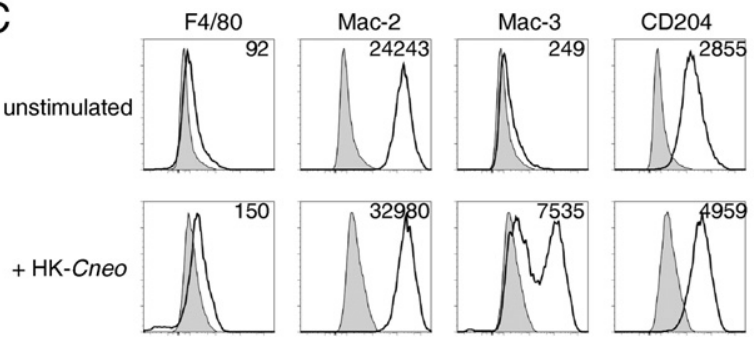

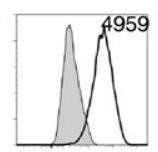

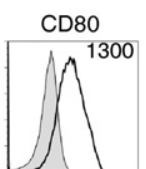

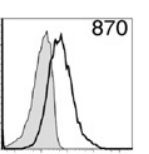

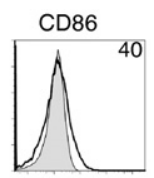

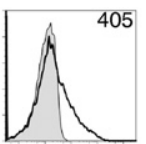

Figure 4. Ly- $6 \mathrm{C}^{\text {high }}$ bone marrow-derived myeloid cells differentiate into $\mathrm{CD} 11 \mathrm{c}^{+} \mathrm{CD}_{11 \mathrm{~b}^{+}}$macrophages in vitro. A: $\mathrm{Ly}-6 \mathrm{C}^{\text {high }}$ myeloid cells isolated from the bone marrow of uninfected wild-type mice were either analyzed immediately (D0) or cultured for 7 days in GM-CSF $(20 \mathrm{ng} / \mathrm{ml})$, when nonadherent cells were discarded and the remaining tightly adherent cells were removed for further analysis (day 7). Left: Expression of Ly-6C (shaded histogram, isotype staining; open histogram, specific staining); right coexpression of CD11c and CD11b (rectangular gate identifies double-positive cells). The expression of Ly- $6 \mathrm{C}$ decreased, whereas the expression of CD11c and CD11b increased, over time in culture. B: Representative photomicrographs of adherent cells after culture, as previously described, in GM-CSF alone [unstimulated (left)] or in GM-CSF with the addition of heat-killed C. neoformans (HK-Cneo) on days 6 to

7 (right) $(\times 100$ objective for both). The ingested cryptococci (arrows) are identified in cells exposed to HK-Cneo. C: Representative histograms of receptor expression on adherent cells after 7 days of culture in media containing GM-CSF alone (unstimulated) or GM-CSF with the addition of HK-Cneo on days 6 to 7 (HK-Cneo). Numbers located above the histograms represent the change in mean fluorescent intensity (MFI) between specific antibody and isotype staining. The experiment was performed three times with similar results.
(7-14 dpi) are newly differentiated from a Ly-6Chigh myeloid precursor.

\section{Ly-6C high Bone Marrow-Derived Myeloid Cells Differentiate in Vitro into $C D 11 c^{+} C D 11 b^{+}$Cells Displaying an ExM Phenotype}

Next, we directly tested whether Ly- $6 C^{\text {high }}$ myeloid cells differentiate into cells displaying an ExM phenotype. Ly- $6 \mathrm{C}^{\text {high }}$ bone marrow-derived myeloid cells isolated from uninfected wild-type mice were small cells containing little cytoplasm (data not shown). They expressed high amounts of Ly-6C and modest amounts of CD11b and did not express CD11c (Figure 4A, D0). Purified Ly-6C ${ }^{\text {high }}$ myeloid cells were cultured for 7 days in GM-CSF, a cytokine uniquely expressed in relatively high amounts in the lung microenvironment. ${ }^{58}$ Thereafter, DCs were discarded with the nonadherent cell population; and the macrophages tightly adherent to the tissue culture plates were collected. Recovered adherent cells no longer expressed Ly-6C but strongly expressed both CD11C and CD11b (Figure 4A, day 7). These cells were large, displayed membrane invaginations and cytoplasmic vacuoles (Figure 4B, unstimulated), and avidly ingested numerous heat-killed cryptococci added to cell cultures (Figure 4B, heat-killed C. neoformans strain 602). Unstimulated $\mathrm{CD} 11 \mathrm{c}^{+} \mathrm{CD} 11 \mathrm{~b}^{+}$ adherent cells expressed F4/80, Mac-2, CD204, and CD80. The expression of Mac-3 and CD86 was low initially but increased after stimulation with heat-killed cryptococci (Figure 4C). Thus, Ly-6C $C^{\text {high }}$ bone marrow-derived myeloid cells can differentiate into highly phagocytic cells displaying a phenotype similar to that of ExMs in the lungs of mice with cryptococcal lung infection.

\section{ExM Accumulation Is Associated with an Early CCR2-Mediated Increase in Ly-6Chigh Monocytes in the Blood and Spleen of Mice that Clear Cryptococcal Lung Infection}

CCR2 mediates the egress of Ly-6Chigh myeloid cells from the bone marrow into the blood of $\mathrm{CCR} 2^{+/+}$ (BALB/c) mice that clear cryptococcal lung infection. ${ }^{45}$ Within the blood, these cells are defined as Ly- $6 C^{\text {high }}$

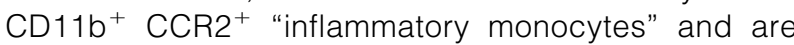
distinct from populations of "resident" or "patrolling" monocytes that express markedly less Ly-6C and CCR2 but strongly express the fractalkine receptor, $\mathrm{CX} 3 \mathrm{C}$ chemokine receptor $1\left(\mathrm{CX}_{3} \mathrm{CR}_{1}\right){ }^{59,60}$ Additional studies in a noninfectious model of vascular injury have suggested that the spleen may participate in the kinetics of monocyte trafficking by acting as a monocyte reservoir. ${ }^{61}$ Whether the spleen serves a similar purpose in response to an infection located in a peripheral organ has not been investigated. To address this question, we used flow cytometric analysis to identify Ly-6C high monocytes (defined as Ly-6C ${ }^{\text {high }}$ CD11 b ${ }^{+}$ cells ${ }^{45}$ ) in the peripheral blood, bone marrow, and spleen during the time of maximal ExM accumulation in the lungs of infected mice (between 0 and 14 dpi). Our results confirm that the frequency of Ly- $6 \mathrm{C}^{\text {high }}$ monocytes increased progressively in peripheral blood mononuclear cells obtained from $\mathrm{CCR}^{+/+}$mice but not from CCR2 ${ }^{-/-}$mice (Figure $5 \mathrm{~A})$. Within bone marrow, the numbers of $\mathrm{Ly}-6 \mathrm{C}^{\text {high }}$ monocytes were significantly increased in CCR2 ${ }^{-1-}$ mice (relative to $\mathrm{CCR}^{+/+}$mice) at D0 and $7 \mathrm{dpi}$ (Figure 5B), consistent with impaired egress. In the spleens of $\mathrm{CCR}^{+/+}$mice, Ly- $6 C^{\text {high }}$ monocytes first increased between DO and $7 \mathrm{dpi}$ (peaking at $1.1 \pm 0.3 \times 10^{6}$ monocytes/spleen, a threefold increase) but then decreased by $14 \mathrm{dpi}$. No increase in Ly- $6 C^{\text {high }}$ monocytes was observed in the spleens of $\mathrm{CCR} 2^{-1-}$ mice, and they were significantly reduced relative 
A

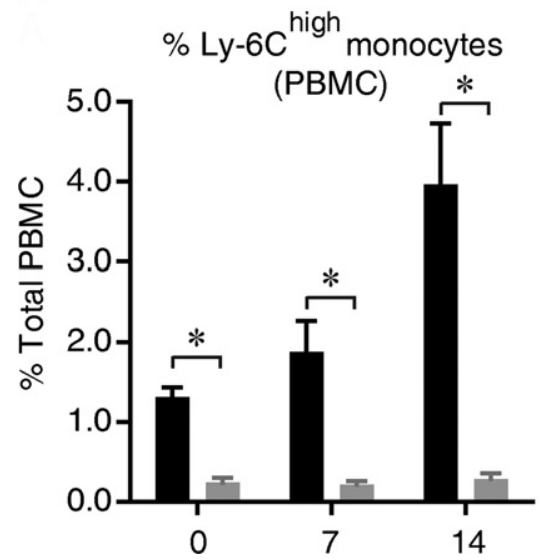

B

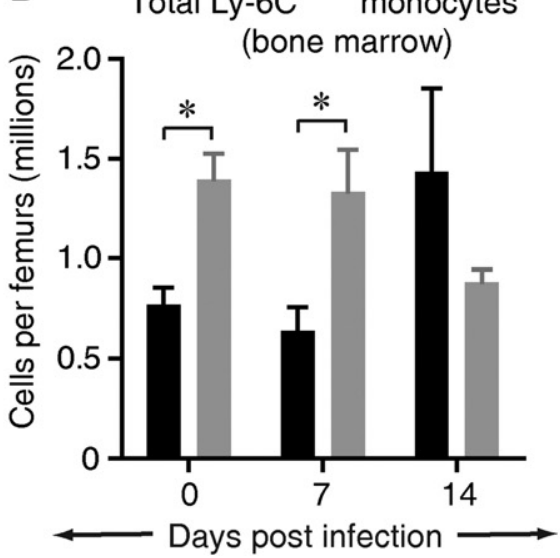

C

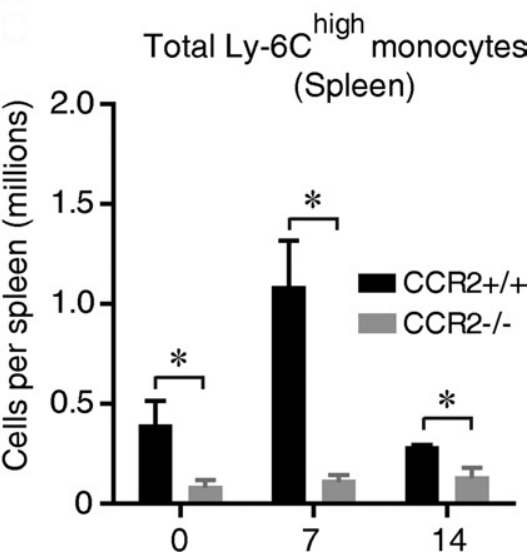

Figure 5. CCR 2 mediates the early accumulation of Ly- $6 C^{\text {high }}$ monocytes in the peripheral blood and spleens of mice that clear cryptococcal lung infection. Organ-specific leukocytes were obtained from CCR $2^{+/+}$mice (wild type, BALB/c) or syngeneic CCR2 $2^{-/-}$mice that were either uninfected (designated D0) or at $7,14,21$, and $28 \mathrm{dpi}$ with $C$. neoformans. Leukocytes were stained with specific antibodies and analyzed by flow cytometric analysis to identify Ly-6C high monocytes (defined as $\mathrm{CD} 45^{+}$Ly- $6 \mathrm{C}^{\text {high }} \mathrm{CD} 11 \mathrm{~b}{ }^{+}$cells). A through $\mathbf{C}$ : Kinetic analysis of Ly- $6 \mathrm{C}^{\text {high }}$ monocytes during cryptococcal lung infection in peripheral blood mononuclear cells (PBMCs) (A), bone marrow (B), and spleen (C). Data in A are the frequency of Ly- $6 \mathrm{C}^{\text {high }}$ monocytes within PBMCs. Data in B and C are total numbers of Ly- $6 \mathrm{C}^{\text {high }}$ monocytes in each tissue; the mean \pm SEM of three to seven mice was assayed individually per point; CCR2 ${ }^{+/+}$mice, black bars; CCR2 ${ }^{-/-}$ mice, gray bars. ${ }^{*} P<0.05$ by unpaired Student's $t$-test between groups at the same point.

to $\mathrm{CCR} 2^{+/+}$mice at all three points (Figure $5 \mathrm{C}$ ). The sequential increase (between 0 and $7 \mathrm{dpi}$ ), then decrease (between 7 and $14 \mathrm{dpi}$ ), in Ly-6Chigh monocytes in the spleen when their numbers are progressively increasing in the blood suggests that the spleen acts as a dynamic reservoir that releases additional Ly- $6 C^{\text {high }}$ monocytes into the circulation during the pre-effector phase of the host response to cryptococcal lung infection.

\section{ExM Accumulation Is Associated with an Early CCR2-Mediated Increase in F4/80 $\mathrm{Ly}$-6C $\mathrm{C}^{\text {high }}$ Monocytes in the Lungs of Mice that Clear Cryptococcal Lung Infection}

Next, we identified monocytes within $\mathrm{CD} 45^{+}$lung leukocytes obtained from the lungs of $\mathrm{CCR} 2^{+/+}$mice at $7 \mathrm{dpi}$ using flow cytometric analysis. Initial gates excluded lymphocytes and eosinophils (data not shown). Thereafter, CD11c-expresssing lung DCs and macrophages were excluded (Figure 6A, left dot plot, gate R2); and lung monocytes were identified as CD11 ${ }^{-} \mathrm{F} 4 / 80^{+} \mathrm{CD}_{11 \mathrm{~b}^{+}}$ cells (Figure 6A, right dot plot, gate "mono"). F4/80 was used as a general marker of lung myeloid cells, including inflammatory and patrolling monocytes. However, nearly all of the lung monocytes we identified expressed high amounts of Ly-6C at all points after infection (Figure 6B and data not shown), consistent with the "Ly-6Chigh inflammatory monocyte" phenotype identified in the peripheral blood of these mice. Further characterization of sorted $\mathrm{F} 4 / 80^{+}$Ly-6Chigh lung monocytes by visual inspection and flow cytometric analysis confirmed that these cells were smaller and had less cytoplasm than lung macrophages (Figure 6, C and D). Similar to ExMs, they strongly expressed CD204 and variable amounts of Mac-2, Mac-3, and CD205 (Figure 6E). F4/80+ Ly-6C ${ }^{\text {high }}$ lung monocytes expressed moderate amounts of $\mathrm{MHC}$ class II, whereas expression of the costimulatory molecules CD40, CD80, and CD86 was low (data not shown).

$\mathrm{F} 4 / 80^{+}$Ly-6C $\mathrm{C}^{\text {high }}$ monocytes were rare in the lungs of uninfected $\mathrm{CCR}^{+/+}$mice and $\mathrm{CCR}^{-1-}$ mice (Figure $6 \mathrm{~F})$. In $\mathrm{CCR}^{+/+}$mice, their numbers significantly increased by $7 \mathrm{dpi}$ and peaked at $14 \mathrm{dpi}(7.1 \% \pm 0.1 \%$ of total CD $45^{+}$leukocytes and $1.2 \pm 0.1 \times 10^{6} \mathrm{~F} 4 / 80^{+}$ Ly-6Chigh monocytes per mouse). This change represented a 53-fold increase relative to uninfected $\mathrm{CCR} 2^{+/+}$ mice. By contrast, total numbers of lung F4/80 ${ }^{+}$Ly- $6 C^{\text {high }}$ monocytes in $\mathrm{CCR}^{-1-}$ mice were markedly diminished, with the maximal difference $(91 \%$ decrease compared with $\mathrm{CCR}^{+/+}$mice) occurring at $7 \mathrm{dpi}$. Collectively, these data demonstrate the CCR2 dependence of F4/ $80^{+}$Ly-6C ${ }^{\text {high }}$ monocyte accumulation in mice that effectively clear pulmonary cryptococcal lung infection.

\section{Accumulation of ExMs, But Not AMs, Is CCR2 Dependent}

CCR2-deficient mice do not clear cryptococcal lung infection. ${ }^{31,32}$ We sought to determine whether this defect in host defense was associated with impaired accumulation of either AMs or ExMs. In uninfected mice (D0), there were no differences between CCR2 ${ }^{+/+}$(wild-type) mice and $\mathrm{CCR}^{-1-}$ mice in either AM or ExM populations (Figure 7, A and B). Consistent with prior studies, ${ }^{31,32,41}$ infection of $\mathrm{CCR} 2^{-1-}$ mice with $C$. neoformans resulted in diminished accumulation of lung leukocytes (data not shown). However, AMs were not significantly reduced in $\mathrm{CCR}^{-/-}$mice (relative to $\mathrm{CCR} 2^{+/+}$mice) at any point after infection (Figure 7A). In contrast, total numbers of ExMs were significantly reduced in the lungs of $\mathrm{CCR}^{-/-}$ mice at all points after infection, with the greatest reduction (83\%) at $14 \mathrm{dpi}$ (Figure 7B). Thus, accumulation of ExMs, but not of AMs, is CCR2 dependent and peak ExM accumulation at 14 to $21 \mathrm{dpi}$ immediately follows 
A

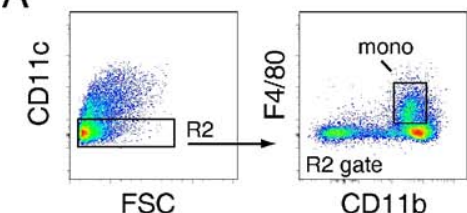

B

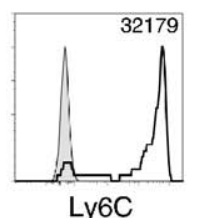

C

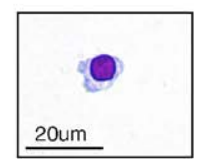

D

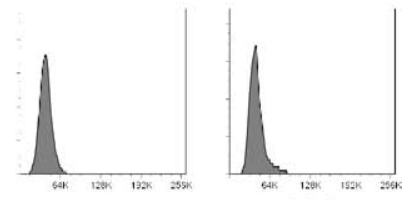
FSC

SSC

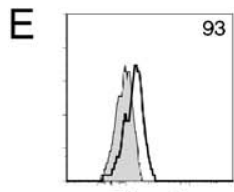

Mac 2

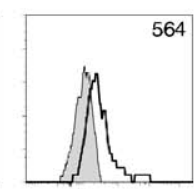

Mac 3

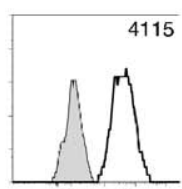

CD204

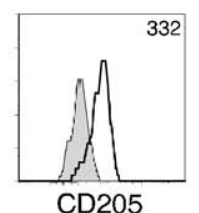

CD205
F

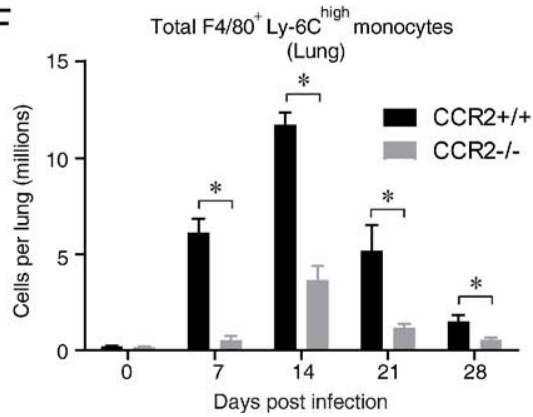

Figure 6. CCR 2 mediates the early accumulation of $\mathrm{F} 4 / 80^{+}$Ly- $6 \mathrm{C}^{\text {high }}$ monocytes in the lungs of mice that clear cryptococcal lung infection. A through E: Lung leukocytes from cryptococcal-infected CCR $2^{+/+}$(wild-type, BALB/c) mice at 7 dpi were stained and analyzed by flow cytometry. A: Gating strategy to identify monocytes: within CD11 $\mathrm{c}^{-}$cells (left dot plot, gate R2 to distinguish this gate from gate R1 in Figure 1), monocytes are identified as $\mathrm{F} 4 / 80^{+} \mathrm{CD} 11 \mathrm{~b}^{+}$cells (right dot plot, gate mono). B through E: Phenotypic analysis of $\mathrm{F} 4 / 80^{+}$monocytes, including the following: expression of Ly-6C (B), morphological features (photomicrograph of cells purified by cell sorting; $\times 100$ objective; hematoxylin-eosin stain) (C), scatter properties (D), and expression of Mac-2, Mac-3, CD204, and CD205 (E). Shaded histogram, isotype staining; open histogram, specific staining. Numbers located above the histograms represent the change in mean fluorescence intensity (MFI) between specific antibody and isotype staining. Nearly all F4/80 $0^{+}$monocytes express high amounts of Ly-6C. F: Kinetic analysis of $\mathrm{F} 4 / 80^{+}$Ly- $6 \mathrm{C}^{\text {high }}$ monocytes in the lungs of CCR $2^{+/+}$(wild-type) mice and syngeneic CCR $2^{-/-}$mice during cryptococcal infection. Data are the mean \pm SEM of three to six mice assayed individually per point; CCR $2^{+/+}$mice, black bars; CCR $2^{-/-}$mice, gray bars. ${ }^{*} P<0.05$ by unpaired Student's $t$-test between groups at the same point. The time course was repeated once ( $n=3$ mice per strain per point) in its entirety with similar results.

the maximal accumulation of $\mathrm{F} 4 / 80^{+} \mathrm{Ly}-6 \mathrm{C}^{\text {high }}$ monocytes (at 7-14 dpi, Figure 6F), providing further evidence that ExMs are derived from this recruited monocyte population.

\section{ExMs Are Classically Activated and Fungicidal}

Our final objective was to evaluate the effector functions of ExMs. First, to verify that ExMs are phagocytic in vivo, we assessed AMs and ExMs for the presence of intracellular cryptococci at the onset of the effector phase against the organism. AMs and ExMs were sorted from the lungs of cryptococcal-infected $\mathrm{CCR}^{+/+}$(wild-type) mice at $14 \mathrm{dpi}$. Equal numbers of macrophages were lysed, and cultures were maintained for 24 hours to quantify the intracellular fungal burden by CFU assay. Relatively few AMs contained fungus at this time, with an average of $0.008 \pm 0.001$ cryptococci per AM (or, on average, 1 cryptococci per $127 \pm 22$ AMs). In contrast, cryptococci were significantly more likely to reside within ExMs at $0.035 \pm 0.002$ cryptococci per ExMs $(P=0.02$, or 1 cryptococci per $28.0 \pm 0.1$ ExMs). Thus, ExMs display phagocytic function. Because the total number of ExMs significantly exceeds that of AMs at this time (Figure $1 \mathrm{E}$ ), these data document that ExMs, not AMs, contain most intracellular cryptococci at the onset of cryptococcal clearance in this model.

Second, we evaluated the expression of two molecules iNOS and TNF- $\alpha$, that are critically important in mediating antifungal host defense. ${ }^{12,18,23,62-67}$ Whole lung mRNA expression of iNOS and TNF- $\alpha$ was similar in uninfected $\mathrm{CCR}^{+/+}$mice and $\mathrm{CCR} 2^{-/-}$mice (data not shown). However, the expression of iNOS and TNF- $\alpha$ was signif- icantly increased in $\mathrm{CCR} 2^{+/+}$mice relative to $\mathrm{CCR} 2^{-/-}$ mice at $14 \mathrm{dpi}$ (Figure 8A). The expression of iNOS was maximal at $14 \mathrm{dpi}$ but remained significantly elevated in $\mathrm{CCR}^{+/+}$mice (relative to $\mathrm{CCR} 2^{-1-}$ mice) at $21 \mathrm{dpi}$, whereas there was no longer a difference in TNF- $\alpha$ expression at this point (data not shown). We used flow cytometric analysis and the gating strategy previously outlined (Figure 1) to demonstrate that both ExMs and AMs present in the lungs of cryptococcal-infected mice at 14 dpi expressed iNOS (Figure 8B). To confirm that this enzyme was biologically active, ExMs and AMs were purified by cell sorting and nitrite production was assayed in vitro. Freshly isolated ExMs and AMs produced measurable amounts of nitrite that were further increased by stimulation with heat-killed $C$. neoformans (Figure $8 \mathrm{C}$ ). The expression of iNOS and nitrite production both tended to be greater in ExMs than in AMs. Both macrophage subsets spontaneously produced TNF- $\alpha$, which was further enhanced on stimulation with heat-killed $C$. neoformans (Figure 8D).

Third, we determined the activation phenotype of ExMs in the lungs of infected $\mathrm{CCR} 2^{+/+}$mice. ExMs were isolated at 14 dpi by cell sorting and expression of iNOS, a gene associated with classic macrophage activation, which was compared relative to the expression of YM2 (a chitinase family member protein), FIZZ1 (found in inflammatory 1 zone protein), and Arg1 (arginase); these are genes associated with alternative macrophage activation. ${ }^{16-18,23}$ Results show a marked increase (>1500-fold over baseline) in iNOS expression relative to the increases observed for YM2, FIZZ1, and Arg1 (Figure 8E). Thus, ExMs within CCR2 ${ }^{+/+}$mice with cryptococcal lung infection were classically activated. 
A
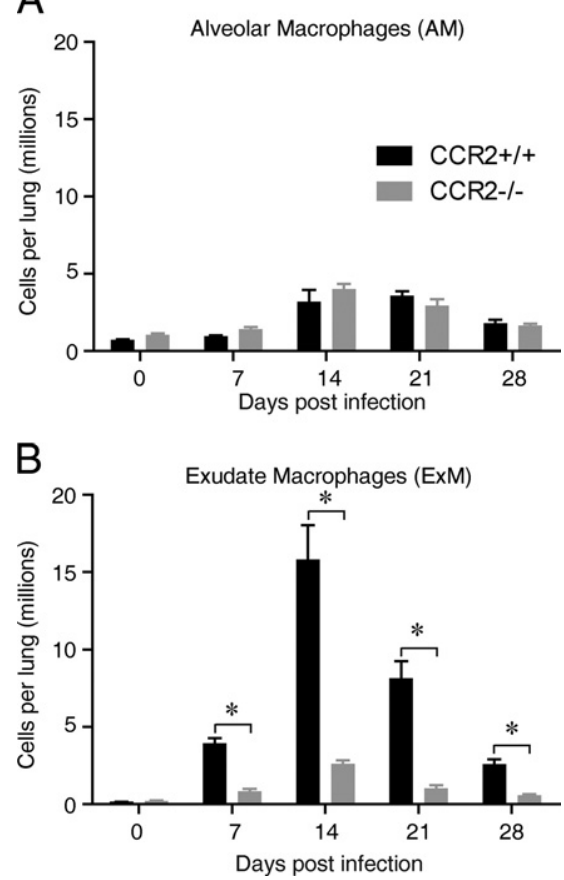

Figure 7. CCR2 mediates the accumulation of ExMs, but not AMs, in mice that clear cryptococcal lung infection. Lung leukocytes were obtained from CCR2 $2^{+/+}$ (wild-type, BALB/c) mice and syngeneic CCR2 ${ }^{-1-}$ mice at D0 (uninfected) or at $7,14,21$, and 28 dpi. The total numbers of AMs (A) and ExMs (B) at each point were calculated by multiplying the frequency of each population identified by flow cytometry by the total number of $\mathrm{CD} 45^{+}$lung leukocytes. Data represent the mean \pm SEM of three to six mice assayed individually per point; CCR2 ${ }^{+/+}$ mice, black bars; CCR $2^{->-}$mice, gray bars. ${ }^{*} P<0.05$ by unpaired Student's $t$-test between groups at the same point. The time course was repeated once ( $n=3$ mice per strain) in its entirety with similar results.

Fourth, we tested whether ExMs are fungicidal. Because of the paucity of ExMs obtained from infected $\mathrm{CCR}^{-1-}$ mice, we isolated these macrophages from the bone marrow of naïve CCR2 ${ }^{++}$(wild-type) and CCR2 ${ }^{-1-}$ mice and compared their fungicidal activity at baseline and on further activation with IFN- $\gamma$ and TNF- $\alpha$ (Figure $8 F)$. AMs obtained from naïve CCR2 ${ }^{+/+}$(wild-type) mice were used for additional comparative purposes. As shown previously, ${ }^{49}$ resting AMs were not fungicidal; progressive cryptococcal growth was observed, although some inhibition occurred when AMs were first cytokine activated. In contrast, ExMs from both $\mathrm{CCR} 2^{+/+}$mice and $\mathrm{CCR}^{-1-}$ mice were highly fungicidal; near-complete fungal clearance was observed using the same effector/target ratios used to test AMs. No differences in fungicidal activity were observed between ExMs derived from either $\mathrm{CCR} 2^{+/+}$mice or $\mathrm{CCR} 2^{-/-}$mice when higher effector/target ratios were used (data not shown). Collectively, we conclude that ExMs in mice that clear cryptococcal lung infection are classically activated and fungicidal.

\section{Discussion}

The results of this study define ExMs as the critical effector macrophage population accumulating in murine lungs during the protective immune response against the fungal pathogen, C. neoformans. The following novel, previ- ously unpublished, observations support this assertion. First, our extensive phenotypic and kinetic analysis reveals that ExMs significantly outnumber AMs during the effector phase of this response. Second, ExMs express numerous receptors associated with pathogen recognition and uptake and are distinguished from AMs by their strong expression of $\mathrm{MHC}$ class II and modest expression of costimulatory molecules. Third, ExMs are classically activated and fungicidal; this potent effector function may be mediated by ExM production of iNOS and TNF- $\alpha$. Fourth, ExM accumulation in response to cryptococcal lung infection is CCR2 dependent and results from the release and differentiation of bone marrow-derived $L y-6 C^{\text {high }}$ monocytes, with the spleen serving as a dynamic monocyte reservoir in this process. We conclude that clearance of cryptococcal lung infection is impaired in CCR2-deficient mice is attributable to the lack of sufficient numbers of fungicidal ExMs. These findings provide key insights into the mechanisms responsible for host defense against pulmonary infection with a eukaryotic fungal pathogen.

Our data show that infection with a facultative intracellular fungal pathogen, $C$. neoformans, stimulates the massive accumulation of ExMs (approximately 10-15 million cells) in the lung. This finding was facilitated by our use of multiparameter flow cytometric analysis in conjunction with specific and consistently applied gating strategies that distinguish numerous myeloid cell subsets. Our use of $\mathrm{AF}$ to distinguish macrophages $\left(\mathrm{AF}^{+}\right)$from lung $\mathrm{DCs}$ $\left(\mathrm{AF}^{-}\right)$represents a critical step in our identification process because both cell types express CD11c. This distinction, well described in two prior studies ${ }^{41,45}$ and in other infectious and noninfectious models of pulmonary inflammation, ${ }^{42,51-53,68}$ permits more specific identification and enumeration of macrophage and DC populations in the lungs of mice. In our model, $\mathrm{AF}^{+}$macrophages, purified by cell sorting, are large cells (with high forward and side scatter) displaying numerous intracytoplasmic vacuoles, some containing cryptococci, consistent with macrophage morphological features (Figure 1). In contrast, purified $\mathrm{AF}^{-}$DCs are smaller than macrophages (with lower forward and side scatter) and contain fewer vacuoles; however, they display more cytoplasmic extensions, consistent with DC morphological features. ${ }^{45}$ Our gating strategy distinguishes ExMs from AMs, which are both $\mathrm{CD}_{11 \mathrm{c}^{+}} \mathrm{AF}^{+}$on the basis of $\mathrm{CD} 11 \mathrm{~b}$ expression (present on ExMs and absent on AMs), as recently described. ${ }^{33-36}$ In those studies, ExMs were specifically identified in the lungs of mice with bacterial or viral pneumonia, in which the numbers were much smaller than in the current study. The impressive quantity of ExMs that we identify in this model likely reflects the substantial inflammation induced by cryptococcal lung infection, with recruitment of up to 100 million CD45 ${ }^{+}$leukocytes per mouse and critical reliance on lung macrophages for clearance of this organism. ${ }^{21,24}$

Our detailed comparative analysis of AM and ExM cell surface phenotype further distinguishes these two populations and also suggests that they differ in their biological function within the lung. Both AMs and ExMs express the receptors F4/80, Mac-2, Mac-3, CD204, and CD205, 
A
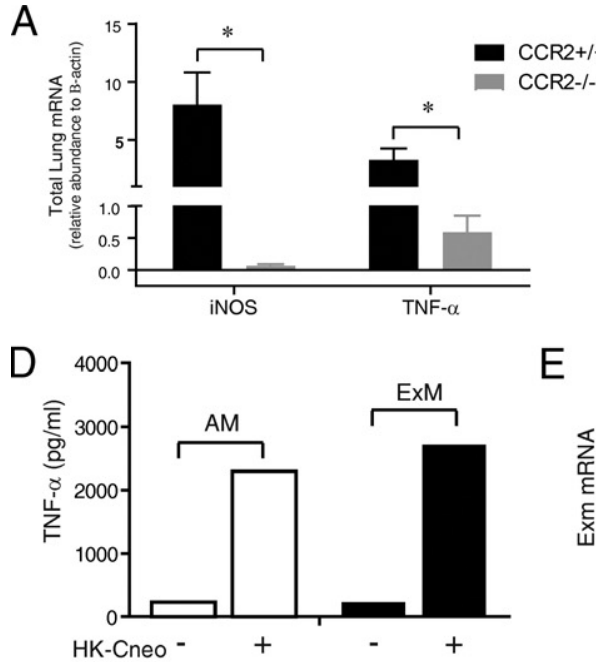

B
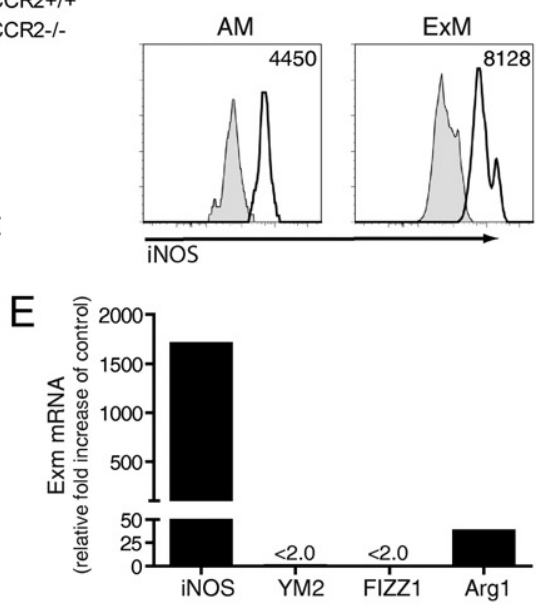

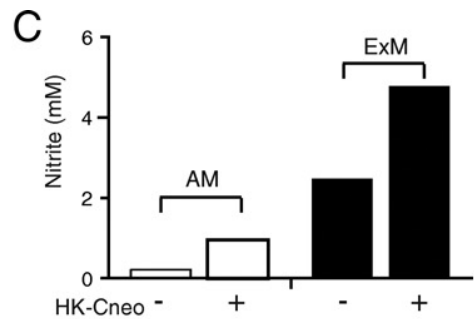

$\mathrm{F}$

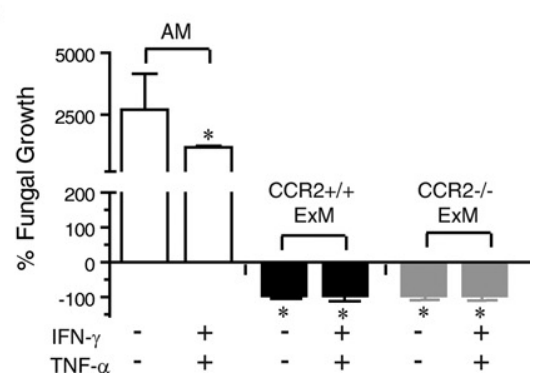

Figure 8. ExMs are classically activated effector macrophages. A: mRNA was extracted from whole lung homogenates obtained from CCR2 $+/+$ (wild-type $\mathrm{BALB} / \mathrm{c}$ ) mice and syngeneic CCR $2^{-/-}$mice at $14 \mathrm{dpi}$ and assessed for expression of iNOS and TNF- $\alpha$ (relative to $\beta$-actin). The break in the $y$ axis allows better visualization of gene expression in CCR $2^{-/-}$mice. Data represent the mean \pm SEM of three to four mice assayed individually per point; CCR $2^{+/+}$mice, black bars; CCR $2^{-1-}$ mice, gray bars. ${ }^{*} P<0.05$ by unpaired Student's $t$-test. B through $\mathbf{E}$ : Lung leukocytes were obtained from cryptococcal-infected CCR ${ }^{+/+}$mice at 14 dpi. B: Representative histograms obtained by flow cytometric analysis depicting intracellular antibody staining for iNOS within AMs (left) and ExMs (right). Shaded histogram, isotype staining; open histogram, specific staining. Numbers located above the histograms represent the change in mean fluorescent intensity (MFI) between specific antibody and isotype staining. $\mathbf{C}$ through $\mathbf{E}$ : AMs and ExMs were purified by cell sorting from pooled lung leukocytes $(n=3$ mice at 14 dpi). C and D: After culture for 24 hours in medium alone, or with heat-killed C. neoformans, supernatants from AMs and ExMs were removed and assessed for production of nitrite (by Griess assay) (C) and TNF- $\alpha$ (by enzyme-linked immunosorbent assay) (D). This experiment was repeated once with similar results. E: mRNA obtained from freshly isolated ExMs was assessed for expression of genes associated with classical (iNOS) or alternative (YM2, FIZZ, and Arg1) macrophage activation using quantitative PCR. ExM gene expression was normalized to glyceraldehyde-3-phosphate dehydrogenase (GAPDH) and expressed as the relative fold increase compared with control mRNA obtained from the total adherent macrophage population present in the lungs of uninfected mice. The break in the $y$ axis allows better visualization of Arg1 expression. The strong iNOS expression (relative to YM2, FIZZ, or Arg1) indicates that ExMs are classically activated. This experiment was repeated twice with similar results. F: Comparison of in vitro fungicidal activity of AMs (from uninfected CCR2 ${ }^{+/+}$mice) versus bone marrow-derived ExMs (obtained from uninfected CCR2 ${ }^{+/+}$mice or CCR2 ${ }^{-/-}$mice) at baseline or in response to additional culture with IFN- $\gamma$ and TNF- $\alpha$, per the Materials and Methods section Cryptococcus neoformans Killing Assay. Progressive cryptoccocal growth was evident in AM cultures (also, a scale change was included on the $y$ axis), whereas nearly complete clearance occurred in ExM cultures of both CCR2 ${ }^{+/+}$and CCR $2^{-/-}$cells. ${ }^{*} P<0.05$ versus unstimulated AMs by unpaired Student's $t$-test. This experiment was repeated once with similar results.

which likely contribute to pathogen recognition and phagocytosis. In contrast, ExMs are distinguished from AMs by their stronger expression of $\mathrm{MHC}$ class II and the costimulatory molecules CD40, CD80, and CD86. This phenotypic distinction suggests that ExMs are better equipped than AMs to interact with antigen-specific IFN$\gamma$-producing $T$ cells, which also begin arriving at 14 dpi. ${ }^{31,32}$ Similarly, ExMs in the lungs of mice infected with influenza or Mycobacterium tuberculosis, pathogens also requiring an adaptive immune response for clearance, also express $\mathrm{MHC}$ class $\mathrm{II}$ and costimulatory molecules. ${ }^{33,34}$ In contrast, ExMs express little MHC class II or CD86 in the lungs of mice infected with Streptococcus pneumoniae, an extracellular bacterial pathogen cleared primarily by innate mechanisms. ${ }^{35}$ We further show that expression of macrophage-associated proteins and costimulatory molecules is not uniform but varies at different times after infection. Collectively, these data imply that the ExM phenotype may vary according to the following: i) the class of infecting pathogen, ii) whether innate or adaptive immune mechanisms are required for microbial clearance, and iii) the inflammatory milieu within the pulmonary microenvironment during different phases of infection. Further investigation of these hypotheses is of considerable interest and warrants future study.

In this study, we define for the first time that ExMs are required for microbial clearance in mice with cryptococ- cal lung infection. Our data reveal that the numbers of ExMs, not AMs, are profoundly diminished in CCR2-deficient mice, which we have previously shown do not clear cryptococcal lung infection. ${ }^{31,32}$ We further show that ExMs, but not AMs, are classically activated and fungicidal. Results from our study suggest that this fungicidal activity may be mediated by iNOS and TNF- $\alpha$. ExMs express more iNOS than AMs in vivo and produce more nitrite, a product of active iNOS, after cryptococcal stimulation in vitro. Both AMs and ExMs express comparable amounts of TNF- $\alpha$. The results of our kinetic analysis suggest that ExMs are the predominant macrophage source of these effector molecules because both iNOS and TNF- $\alpha$ are significantly diminished in CCR2-deficient mice in which ExMs are scarce. Previous investigations $^{12,18,23,62-67}$ have defined iNOS and TNF- $\alpha$ expression as strong predictors of cryptococcal killing in vitro and clearance of the organism in vivo, although other effector mechanisms may also contribute to ExM fungicidal activity. Additional studies are also required to understand whether and how these cells interact with other critical leukocyte populations that we have previously identified, including DCs and IFN- $\gamma$-producing T cells. ${ }^{32,41}$ Last, our data demonstrate that CCR2-deficient ExMs retain their fungicidal capability. Collectively, we conclude that the failure of CCR2-deficient mice to clear 
cryptococcal lung infection significantly relates to their relative absence of fungicidal ExMs.

The second major conclusion of our study is that ExM accumulation in mice with cryptococcal lung infection results from the recruitment and differentiation of Ly$6 \mathrm{C}^{\text {high }}$ monocytes. The current data showing that cryptococcal lung infection triggers the CCR2-mediated egress of Ly- $6 C^{\text {high }}$ inflammatory monocytes from the bone marrow agree with and extend the previous finding ${ }^{45}$ and results obtained in other model systems. ${ }^{69-71}$ The upregulation of two CCR2 ligands, CC chemokine ligands 2 and 7 , in the lung at $7 \mathrm{dpi}^{41}$ correlates with a parallel increase in Ly-6C $\mathrm{C}^{\text {high }}$ monocyte in the blood and lung, suggesting rapid transit from marrow to lung. Ly- $6 C^{\text {high }}$ monocytes may briefly reside in the spleen because their numbers sequentially increased (between 0 and $7 \mathrm{dpi}$ ) and then decreased (between 7 and $14 \mathrm{dpi}$ ) in the spleen, whereas they continually increased in both peripheral blood and lung throughout the pre-effector phase of the host response. This phenomenon of "filling" and "draining" implies that the spleen functions as a dynamic "reservoir" of Ly-6Chigh monocytes in response to lung infection. Our studies extend those of Swirski et $\mathrm{al}^{61}{ }^{61}$ who were the first to identify the spleen as a monocyte reservoir using a murine model of vascular inflammation. The near absence of splenic Ly-6C ${ }^{\text {high }}$ monocytes in cryptococcal-infected CCR2-deficient mice implies that the spleen is "downstream" from the bone marrow. Loss of this splenic reservoir might further explain the impaired monocyte accumulation observed in CCR2-deficient mice in this and other model systems. Collectively, these data further define early CCR2-mediated communication between the lung, bone marrow, and possibly spleen as a critical mechanism regulating the lung's acquisition of ExMs in response to fungal infection.

The understanding of in situ monocyte differentiation within peripheral microenvironments is advanced by the results of our phenotypic and kinetic analysis of lung ExMs and monocyte accumulation in vivo, in concert with our in vitro study of cultured Ly- $6 \mathrm{C}^{\text {high }}$ monocytes. First, the finding that ExMs present in the lung at $7 \mathrm{dpi}$ expressed more Ly-6C than those present at 14 or $21 \mathrm{dpi}$ is consistent with our in vitro culture of Ly-6C $\mathrm{C}^{\text {high }}$ monocytes and with other studies demonstrating loss of $L y-6 C$ expression over time and as myeloid cells differentiate. ${ }^{33,56,57}$ We also show that culture in GM-CSF alone is sufficient to induce up-regulation of CD11c, CD11b, Mac-2, CD204, and CD80; however, the expression of Mac-3 and CD86 requires additional stimulation with Cryptococcus (or lipopolysaccharide; unpublished observations, Osterholzer J). These findings suggest that ExMs are further influenced by their microenvironment. Second, the total numbers of Ly-6C high monocytes in wild-type mice peaked between 7 and 14 dpi (Figure 6), whereas the numbers of ExMs peaked 1 week later (Figures 1 and 7), providing further evidence that in vivo differentiation is not immediate. Loss of Ly- $6 \mathrm{C}$ expression by ExMs in vivo was not attributable to cell division because our results show that ExMs are not proliferating. These findings highlight further the critical link between monocyte recruitment and differentiation and ExM accumulation in the lungs of mice that clear cryptococcal lung infection.

The factors determining the balance of differentiation of Ly- $6 C^{\text {high }}$ monocytes into ExMs versus DCs are not addressed by these studies. This balance may depend on unique regulatory influences in the pulmonary microenvironment. The results of our studies suggest that exposure to chemokines, cytokines, microbes (or microbial products), and their physical location within the lung might all contribute. This model of cryptococcal lung infection is well suited to define further the complex interrelationships between these nonresident myeloid subsets in the organ associated with the most lethal human infections. $^{72}$

In summary, this study identifies ExMs as the critical effector macrophage population in the lungs of mice that effectively clear a fungal pathogen that is highly relevant to human health. The accumulation of effector ExMs depends critically on the recruitment and differentiation of a precursor population of $\mathrm{Ly}-6 \mathrm{C}^{\text {high }}$ monocytes. The results of our study specifically implicate the CCR2 axis as a potential target for novel therapies designed to augment ExM accumulation within the lung for the treatment of infectious or inflammatory pulmonary disease.

\section{References}

1. Hage CA, Wood KL, Winer-Muram HT, Wilson SJ, Sarosi G, Knox KS: Pulmonary cryptococcosis after initiation of anti-tumor necrosis factor-alpha therapy. Chest 2003, 124:2395-2397

2. Kovacs JA, Kovacs AA, Polis M, Wright WC, Gill VJ, Tuazon CU, Gelmann EP, Lane HC, Longfield R, Overturf G:: Cryptococcosis in the acquired immunodeficiency syndrome. Ann Intern Med 1985 103:533-538

3. Kwon-Chung KJ, Sorrell TC, Dromer F, Fung E, Levitz SM: Cryptococcosis: clinical and biological aspects. Med Mycol 2000, 38(Suppl 1):205-213

4. Hoang LMN, Maguire JA, Doyle P, Fyfe M, Roscoe DL: Cryptococcus neoformans infections at Vancouver Hospital and Health Sciences Centre (1997-2002): epidemiology, microbiology and histopathology. J Med Microbiol 2004, 53:935-940

5. Hofman V, Venissac N, Mouroux C, Butori C, Mouroux J, Hofman P. Disseminated pulmonary infection due to Cryptococcus neoformans in a non immunocompromised patient [in French]. Ann Pathol 2004, 24:187-191

6. Zahra LV, Azzopardi CM, Scott G: Cryptococcal meningitis in two apparently immunocompetent Maltese patients. Mycoses 2004, 47: 168-173

7. Rapp RP: Changing strategies for the management of invasive fungal infections. Pharmacotherapy 2004, 24:4S-28S; quiz, 29S-32S

8. Herring AC, Hernandez Y, Huffnagle GB, Toews GB: Role and development of $\mathrm{TH} 1 / \mathrm{TH} 2$ immune responses in the lungs. Semin Respir Crit Care Med 2004, 25:3-10

9. Huffnagle GB, Lipscomb MF: Cells and cytokines in pulmonary cryptococcosis. Res Immunol 1998, 149:387-396; discussion, 512-514

10. Bauman SK, Huffnagle GB, Murphy JW: Effects of tumor necrosis factor alpha on dendritic cell accumulation in lymph nodes draining the immunization site and the impact on the anticryptococcal cellmediated immune response. Infect Immun 2003, 71:68-74

11. Chen GH, McDonald RA, Wells JC, Huffnagle GB, Lukacs NW, Toews GB: The gamma interferon receptor is required for the protective pulmonary inflammatory response to Cryptococcus neoformans. Infect Immun 2005, 73:1788-1796

12. Herring AC, Falkowski NR, Chen GH, McDonald RA, Toews GB, Huffnagle GB: Transient neutralization of tumor necrosis factor alpha can produce a chronic fungal infection in an immunocompetent host: 
potential role of immature dendritic cells. Infect Immun 2005, 73:39-49

13. Huffnagle GB, Lipscomb MF, Lovchik JA, Hoag KA, Street NE: The role of CD4+ and CD8+ T cells in the protective inflammatory response to a pulmonary cryptococcal infection. J Leukoc Biol 1994, 55:35-42

14. Huffnagle GB, Toews GB, Burdick MD, Boyd MB, McAllister KS, McDonald RA, Kunkel SL, Strieter RM: Afferent phase production of TNF-alpha is required for the development of protective T cell immunity to Cryptococcus neoformans. J Immunol 1996, 157:4529-4536

15. Huffnagle GB, Yates JL, Lipscomb MF: T cell-mediated immunity in the lung: a Cryptococcus neoformans pulmonary infection model using SCID and athymic nude mice. Infect Immun 1991, 59:14231433

16. Hardison SE, Ravi S, Wozniak KL, Young ML, Olszewski MA, Wormley FL Jr: Pulmonary infection with an interferon-gamma-producing Cryptococcus neoformans strain results in classical macrophage activation and protection. Am J Pathol 2010, 176:774-785

17. Zhang Y, Wang F, Tompkins KC, McNamara A, Jain AV, Moore BB, Toews GB, Huffnagle GB, Olszewski MA: Robust Th1 and Th17 immunity supports pulmonary clearance but cannot prevent systemic dissemination of highly virulent Cryptococcus neoformans H99. Am J Pathol 2009, 175:2489-2500

18. Arora S, Hernandez Y, Erb-Downward JR, McDonald RA, Toews GB, Huffnagle GB: Role of IFN-gamma in regulating T2 immunity and the development of alternatively activated macrophages during allergic bronchopulmonary mycosis. J Immunol 2005, 174:6346-6356

19. Kawakami K, Qifeng X, Tohyama M, Qureshi MH, Saito A: Contribution of tumour necrosis factor- $\alpha$ (TNF- $\alpha$ ) in host defence mechanism against Cryptococcus neoformans. Clin Exp Immunol 1996, 106:468474

20. Kawakami K, Zhang T, Qureshi MH, Saito A: Cryptococcus neoformans inhibits nitric oxide production by murine peritoneal macrophages stimulated with interferon-gamma and lipopolysaccharide. Cell Immunol 1997, 180:47-54

21. Levitz SM: Macrophage-Cryptococcus interactions. Immunol Ser 1994, 60:533-543

22. Mody $\mathrm{CH}$, Tyler $\mathrm{CL}$, Sitrin RG, Jackson C, Toews GB: Interferongamma activates rat alveolar macrophages for anticryptococcal activity. Am J Respir Cell Mol Biol 1991, 5:19-26

23. Osterholzer JJ, Surana R, Milam JE, Montano GT, Chen GH, Sonstein J, Curtis JL, Huffnagle GB, Toews GB, Olszewski MA: Cryptococcal urease promotes the accumulation of immature dendritic cells and a non-protective T2 immune response within the lung. Am J Pathol 2009, 174:932-943

24. Shoham S, Levitz SM: The immune response to fungal infections. Br J Haematol 2005, 129:569-582

25. Feldmesser $M$, Kress $Y$, Novikoff $P$, Casadevall A: Cryptococcus neoformans is a facultative intracellular pathogen in murine pulmonary infection. Infect Immun 2000, 68:4225-4237

26. Feldmesser M, Tucker S, Casadevall A: Intracellular parasitism of macrophages by Cryptococcus neoformans. Trends Microbiol 2001 9:273-278

27. Goldman DL, Lee SC, Mednick AJ, Montella L, Casadevall A: Persistent Cryptococcus neoformans pulmonary infection in the rat is associated with intracellular parasitism, decreased inducible nitric oxide synthase expression, and altered antibody responsiveness to cryptococcal polysaccharide. Infect Immun 2000, 68:832-838

28. Kechichian TB, Shea J, Del Poeta M: Depletion of alveolar macrophages decreases the dissemination of a glucosylceramide-deficient mutant of Cryptococcus neoformans in immunodeficient mice. Infect Immun 2007, 75:4792-4798

29. Shea JM, Kechichian TB, Luberto C, Del Poeta M: The cryptococcal enzyme inositol phosphosphingolipid-phospholipase $\mathrm{C}$ confers resistance to the antifungal effects of macrophages and promotes fungal dissemination to the central nervous system. Infect Immun 2006, 74:5977-5988

30. Osterholzer JJ, Milam JE, Chen GH, Toews GB, Huffnagle GB, OIszewski MA: Role of dendritic cells and alveolar macrophages in regulating early host defense against pulmonary infection with Cryptococcus neoformans. Infect Immun 2009, 77:3749-3758

31. Traynor TR, Herring AC, Dorf ME, Kuziel WA, Toews GB, Huffnagle GB: Differential roles of CC chemokine ligand 2/monocyte chemotac- tic protein-1 and CCR2 in the development of T1 immunity. J Immuno 2002, 168:4659-4666

32. Traynor TR, Kuziel WA, Toews GB, Huffnagle GB: CCR2 expression determines T1 versus T2 polarization during pulmonary Cryptococcus neoformans infection. J Immunol 2000, 164:2021-2027

33. Lin KL, Suzuki Y, Nakano H, Ramsburg E, Gunn MD: CCR2+ monocyte-derived dendritic cells and exudate macrophages produce influenza-induced pulmonary immune pathology and mortality. J Immunol 2008, 180:2562-2572

34. Skold M, Behar SM: Tuberculosis triggers a tissue-dependent program of differentiation and acquisition of effector functions by circulating monocytes. J Immunol 2008, 181:6349-6360

35. Winter C, Herbold W, Maus R, Langer F, Briles DE, Paton JC, Welte T Maus UA: Important role for CC chemokine ligand 2-dependent lung mononuclear phagocyte recruitment to inhibit sepsis in mice infected with Streptococcus pneumoniae. J Immunol 2009, 182:4931-4937

36. Taut K, Winter C, Briles DE, Paton JC, Christman JW, Maus R, Baumann R, Welte T, Maus UA: Macrophage turnover kinetics in the lungs of mice infected with Streptococcus pneumoniae. Am J Respir Cell Mol Biol 2008, 38:105-113

37. Chen GH, McNamara DA, Hernandez Y, Huffnagle GB, Toews GB Olszewski MA: Inheritance of immune polarization patterns is linked to resistance versus susceptibility to Cryptococcus neoformans in a mouse model. Infect Immun 2008, 76:2379-2391

38. Kuziel WA, Morgan SJ, Dawson TC, Griffin S, Smithies O, Ley K Maeda N: Severe reduction in leukocyte adhesion and monocyte extravasation in mice deficient in CC chemokine receptor 2. Proc Natl Acad Sci U S A 1997, 94:12053-12058

39. Curtis JL, Kim S, Scott PJ, Buechner-Maxwell VA: Adhesion receptor phenotypes of murine lung $\mathrm{CD} 4^{+} \mathrm{T}$ cells during a pulmonary immune response to sheep erythrocytes. Am J Respir Cell Mol Biol 1995, 12:520-530

40. Agger R, Petersen MS, Toldbod HE, Holtz S, Dagnaes-Hansen F Johnsen BW, Bolund L, Hokland M: Characterization of murine dendritic cells derived from adherent blood mononuclear cells in vitro. Scand J Immunol 2000, 52:138-147

41. Osterholzer JJ, Curtis JL, Polak T, Ames T, Chen GH, McDonald R Huffnagle GB, Toews GB: CCR2 mediates conventional dendritic cel recruitment and the formation of bronchovascular mononuclear cell infiltrates in the lungs of mice infected with Cryptococcus neoformans. J Immunol 2008, 181:610-620

42. Osterholzer JJ, Ames T, Polak T, Sonstein J, Moore BB, Chensue SW Toews GB, Curtis JL: CCR2 and CCR6, but not endothelial selectins, mediate the accumulation of immature dendritic cells within the lungs of mice in response to particulate antigen. J Immunol 2005, 175:874883

43. Cappella P, Gasparri F, Pulici M, Moll J: Cell proliferation method: click chemistry based on BrdU coupling for multiplex antibody staining. Curr Protoc Cytom 2008, Chap 7:Unit 7.34

44. Cappella P, Gasparri F, Pulici M, Moll J: A novel method based on click chemistry, which overcomes limitations of cell cycle analysis by classical determination of BrdU incorporation, allowing multiplex antibody staining. Cytometry A 2008, 73:626-636

45. Osterholzer JJ, Chen GH, Olszewski MA, Curtis JL, Huffnagle GB Toews GB: Accumulation of CD11b + lung dendritic cells in response to fungal infection results from the CCR2-mediated recruitment and differentiation of Ly-6Chigh monocytes. J Immunol 2009, 183:80448053

46. Salic A, Mitchison TJ: A chemical method for fast and sensitive detection of DNA synthesis in vivo. Proc Natl Acad Sci U S A 2008 , 105:2415-2420

47. Terashima T, Wiggs B, English D, Hogg JC, van Eeden SF: Polymorphonuclear leukocyte transit times in bone marrow during streptococcal pneumonia. Am J Physiol 1996, 271:L587-L592

48. Kleinbongard $P$, Rassaf $T$, Dejam A, Kerber S, Kelm M: Griess method for nitrite measurement of aqueous and protein-containing samples. Methods Enzymol 2002, 359:158-168

49. Chen $\mathrm{GH}$, Curtis JL, Mody CH, Christensen PJ, Armstrong LR, Toews GB: Effect of granulocyte-macrophage colony-stimulating factor on rat alveolar macrophage anticryptococcal activity in vitro. J Immunol 1994, 152:724-734

50. Zar J: Biostastical Analysis. Englewood Cliffs, NJ, Prentice-Hall, 1974 pp 718 
51. van Rijt LS, Prins JB, Leenen PJ, Thielemans K, de Vries VC, Hoogsteden $\mathrm{HC}$, Lambrecht BN: Allergen-induced accumulation of airway dendritic cells is supported by an increase in CD31(hi)Ly-6C(neg) bone marrow precursors in a mouse model of asthma. Blood 2002, 100:3663-3671

52. Havenith CE, Breedijk AJ, van Miert PP, Blijleven N, Calame W, Beelen RH, Hoefsmit EC: Separation of alveolar macrophages and dendritic cells via autofluorescence: phenotypical and functional characterization. J Leukoc Biol 1993, 53:504-510

53. van Rijt LS, Kuipers H, Vos N, Hijdra D, Hoogsteden HC, Lambrecht $\mathrm{BN}$ : A rapid flow cytometric method for determining the cellular composition of bronchoalveolar lavage fluid cells in mouse models of asthma. J Immunol Methods 2004, 288:111-121

54. Winter C, Taut K, Langer F, Mack M, Briles DE, Paton JC, Maus R, Srivastava M, Welte T, Maus UA: FMS-like tyrosine kinase 3 ligand aggravates the lung inflammatory response to Streptococcus pneumoniae infection in mice: role of dendritic cells. J Immunol 2007. 179:3099-3108

55. Winter C, Taut K, Srivastava M, Langer F, Mack M, Briles DE, Paton JC, Maus R, Welte T, Gunn MD, Maus UA: Lung-specific overexpression of CC chemokine ligand (CCL) 2 enhances the host defense to Streptococcus pneumoniae infection in mice: role of the CCL2-CCR2 axis. J Immunol 2007, 178:5828-5838

56. Sunderkotter C, Nikolic T, Dillon MJ, Van Rooijen N, Stehling M, Drevets DA, Leenen PJ: Subpopulations of mouse blood monocytes differ in maturation stage and inflammatory response. J Immunol 2004, 172:4410-4417

57. Xu H, Manivannan A, Dawson R, Crane IJ, Mack M, Sharp P, Liversidge J: Differentiation to the CCR2+ inflammatory phenotype in vivo is a constitutive, time-limited property of blood monocytes and is independent of local inflammatory mediators. J Immunol 2005, 175: 6915-6923

58. Trapnell BC, Whitsett JA: Gm-CSF regulates pulmonary surfactant homeostasis and alveolar macrophage-mediated innate host defense. Annu Rev Physiol 2002, 64:775-802

59. Auffray C, Sieweke MH, Geissmann F: Blood monocytes: development, heterogeneity, and relationship with dendritic cells. Annu Rev Immunol 2009, 27:669-692

60. Serbina NV, Jia T, Hohl TM, Pamer EG: Monocyte-mediated defense against microbial pathogens. Annu Rev Immunol 2008, 26:421-452

61. Swirski FK, Nahrendorf M, Etzrodt M, Wildgruber M, Cortez-Retamozo V, Panizzi P, Figueiredo JL, Kohler RH, Chudnovskiy A, Waterman P,
Aikawa E, Mempel TR, Libby P, Weissleder R, Pittet MJ: Identification of splenic reservoir monocytes and their deployment to inflammatory sites. Science 2009, 325:612-616

62. Aguirre KM, Gibson GW: Differing requirement for inducible nitric oxide synthase activity in clearance of primary and secondary Cryptococcus neoformans infection. Med Mycol 2000, 38:343-353

63. Chiapello LS, Baronetti JL, Garro AP, Spesso MF, Masih DT: Cryptococcus neoformans glucuronoxylomannan induces macrophage apoptosis mediated by nitric oxide in a caspase-independent pathway. Int Immunol 2008, 20:1527-1541

64. Kawakami K, Tohyama M, Qifeng X, Saito A: Expression of cytokines and inducible nitric oxide synthase mRNA in the lungs of mice infected with Cryptococcus neoformans: effects of interleukin-12. Infect Immun 1997, 65:1307-1312

65. Maffei CM, Mirels LF, Sobel RA, Clemons KV, Stevens DA: Cytokine and inducible nitric oxide synthase mRNA expression during experimental murine cryptococcal meningoencephalitis. Infect Immun 2004, 72:2338-2349

66. Rivera J, Mukherjee J, Weiss LM, Casadevall A: Antibody efficacy in murine pulmonary Cryptococcus neoformans infection: a role for nitric oxide. J Immunol 2002, 168:3419-3427

67. Tohyama M, Kawakami K, Saito A: Anticryptococcal effect of amphotericin $B$ is mediated through macrophage production of nitric oxide. Antimicrob Agents Chemother 1996, 40:1919-1923

68. Nicod LP, Lipscomb MF, Toews GB, Weissler JC: Separation of potent and poorly functional human lung accessory cells based on autofluorescence. J Leukoc Biol 1989, 45:458-465

69. Jia T, Serbina NV, Brandl K, Zhong MX, Leiner IM, Charo IF, Pamer EG: Additive roles for MCP-1 and MCP-3 in CCR2-mediated recruitment of inflammatory monocytes during Listeria monocytogenes infection. J Immunol 2008, 180:6846-6853

70. Serbina NV, Pamer EG: Monocyte emigration from bone marrow during bacterial infection requires signals mediated by chemokine receptor CCR2. Nat Immunol 2006, 7:311-317

71. Tsou CL, Peters W, Si Y, Slaymaker S, Aslanian AM, Weisberg SP, Mack M, Charo IF: Critical roles for CCR2 and MCP-3 in monocyte mobilization from bone marrow and recruitment to inflammatory sites. J Clin Invest 2007, 117:902-909

72. Campanini BaV-F, L: The world health report 2005. Changing History Geneva, Switzerland,. World Health Organization, 2004, pp 127. 